\title{
Associative Learning and Stimulus Novelty Influence the Song-induced Expression of an Immediate Early Gene in the Canary Forebrain
}

\author{
Erich D. Jarvis, Claudio V. Mello, and Fernando Nottebohm \\ The Rockefeller University Field Research Center \\ Millbrook, New York 12545
}

\begin{abstract}
To identify variables that affect immediate early gene (IEG) expression in the auditory telencephalon of songbirds, we developed a conditioning paradigm that trained adult male canaries to associate song with a mild shock. Learning of the association was measured by a bird's fear and avoidance responses. Birds exposed to paired song and shock were compared to yoked controls exposed to each stimulus alone or to both unpaired. Additional groups examined the effects of attention and stress, and of the novelty of the stimulus situation. In situ hybridization analysis of brain sections revealed an enhancement of ZENK expression in birds learning the association between song and shock above levels induced by song alone or yoked-unpaired song and shock. This effect was specifically seen in the caudomedial auditory telencephalon (NCM-HVCM). A comparison of the several control groups indicated that novelty of the song stimulus or of its pairing with shock were the main variables that predicted ZENK levels in NCM-HVCM. These observations are compatible with ZENK playing a role in the formation of song perceptual memories.
\end{abstract}

\section{Introduction}

Recent studies have shown that song playbacks induce the expression of two immediate early genes (IEGs), ZENK and c-jun, in specific regions of the songbird auditory telencephalon (Mello et al. 1992; Mello and Clayton 1994; Nastiuk et al. 1994). These genes encode DNA-binding proteins capable of regulating expression of other genes (Lamph et al. 1988; Nishimura and Vogt 1988; Christy and Nathans 1989; Gupta et al. 1991 ) and they are considered part of a genomic program that coordinates long-term cellular changes in response to neuronal activation (Goelet et al. 1986, Morgan and Curran 1989). The most robust effect of song playbacks on IEG expression is seen with $Z E N K$, also known as zif-268 (Christy et al. 1988), egr-1 (Sukhatme et al. 1988), NGFI-A (Millbrandt et al. 1987), Krox-24 (Lemaire et al. 1988), and TIS8 (Lim et al. 1987), and it is most pronounced in the caudomedial neostriatum (NCM) and in the adjacent caudomedial hyperstriatum ventralis (HVCM).

ZENK expression in NCM-HVCM is particularly high when songbirds hear songs of their own species, moderate when they hear songs of another species, and very low or absent after exposure to non-song auditory stimuli, such as pure tones (Mello et al. 1992). The expression is transient and peaks 30-40 min after onset of stimulation and declines thereafter (Mello and Clayton 1994). Induction ceases to occur with repeated daily exposures to the same song but reappears when a new song is presented (Mello et al. 1995).

Electrophysiological recordings of cells in NCM have shown recently that the response of these cells to a novel song also decreases ("habituates") as that same stimulus is repeated again and again. This habituation lasts for $48 \mathrm{hr}$ when the stimulus used is conspecific song, is shorter lived when heterospecific song is used, and does not occur at all with pure tones (Chew et al. 1995). Thus, the stimuli that are most effective in eliciting

LEARNING \& MEMORY 2:62-80 @ 1995 by Cold Spring Harbor Laboratory Press ISSN1072-0502/95 $\$ 5.00$

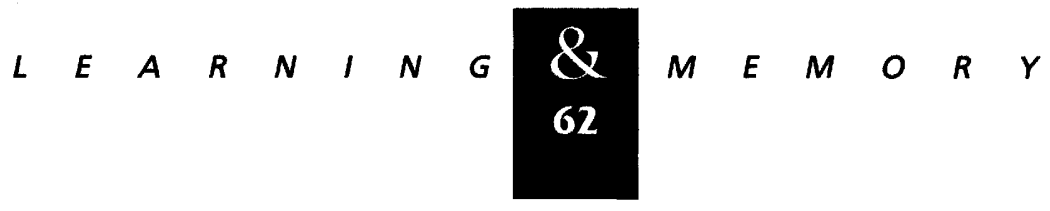


ZENK expression in NCM are also the ones that are most effective in inducing long-term habituation in NCM neurons. In addition, inhibitors of protein or RNA synthesis in NCM block the long- but not the short-term habituation of NCM neurons to repeated playbacks of a song (Chew et al. 1995).

Taken together, these observations suggest, but do not prove, that ZENK expression in NCM plays a role in altering the long-term responsiveness of NCM neurons to a particular song. This mechanism could underlie the formation of song perceptual memories, which in turn determine a bird's response to song.

In the present study, we sought to identify stimulus and experiential variables that influenced ZENK expression in NCM-HVCM. The study describes first, the development of a conditioning paradigm to train songbirds to associate song with a mild electric shock to their feet. The birds learned to avoid the shock by jumping or hovering in the air when they heard the song. This avoidance learning occurred over a relatively short period of time (in one or two 40-min training sessions), which allowed us to relate changes in behavior to levels of ZENK expression in the brain, which is the second part of the study. Birds learning the association between song and shock were compared with matched yoked controls exposed to these two stimuli unpaired, and with several other groups that emphasized the novelty of the song stimulus, the novelty of its pairing with shock, or the degree of stress induced. A good correspondence was seen between associative learning and enhanced ZENK expression in NCM-HVCM.

Earlier reports have related $Z E N K$ expression to the formation of olfactory memories (Brennan et al. 1992) and spatial learning (Fordyce et al. 1994 ) in mice, and to shock avoidance (Nikolaev et al. 1992a,b) and hippocampal long-term potentiation (LTP) (Wisden et al. 1988), a form of synaptic plasticity, in rats. The expression of other IEGs has been related, for example, to the acquisition of pecking selectivity (Anokhin et al. 1991; Anokhin and Rose 1991) and imprinting (McCabe and Horn 1994) in chicks. Ours is the first study that looks at the relation between IEG expression and associative learning related to song in songbirds and that attempts to assess the contribution of factors such as stimulus novelty, attention, and stress. The results we present here are compatible with $Z E N K$ playing a role in associative learning, and raise some new and interesting questions.

\section{Materials and Methods}

\section{ANIMALS}

One hundred thirty-nine adult male canaries (1-2 years old) of the Belgian Waterslager strain, bred at the Rockefeller University Field Research Center (Millbrook, NY), were used. These birds were kept under constant temperature conditions $\left(20^{\circ} \mathrm{C}\right)$ and under a light regime that followed the New York State photoperiod. Birds in each experiment were of the same approximate age. Experiments took place either in the Spring or Fall; the behavioral results were the same regardless of the season except during the molt, when it was difficult to train birds to avoid a shock (not shown). Experiments in the Fall were done after the end of the molt. During the course of an experiment all birds were housed in individual cages located in the same room.

\section{BEHAVIORAL TRAINING}

Canaries were placed singly in a $20 \times 15 \times 20$ inch box made of clear plexiglass that had a metal bar floor and no perches. Birds were presented with a three-phrase, 4.5-sec fragment of canary song [the conditioned stimulus (CS)] paired with a mild $(20 \mu \mathrm{A})$ shock [the unconditioned stimulus (US)] delivered through the floor of the box. The shock occurred $3.5 \mathrm{sec}$ after the start of the song stimulus, halfway into its third phrase (Fig. 1). The birds always responded to the shock by jumping or hovering in the air [the unconditioned response (UR)], with a latency of $<1$ sec. Once the birds' feet broke contact with the metal bar floor, the shock was terminated. However, if the bird broke contact with the floor any time after the song started but before the shock was delivered, no shock was given and the bird scored a correct "avoidance response" [the conditioned response (CR)]. In many instances birds trained with the pairing of song and shock gave, upon hearing the song, a "fear" response that took one of three forms. Birds would either (1) "freeze," sleeking the feathers and grasping the bars of the floor, (2) "crouch," with beak facing upward as in preparation to jump, or (3) "flag their head" rapidly from side to side.

Exposure to song and shock occurred during "sessions" that lasted $40 \mathrm{~min}$ and included 80 "trials." We chose a 40-min session because we know

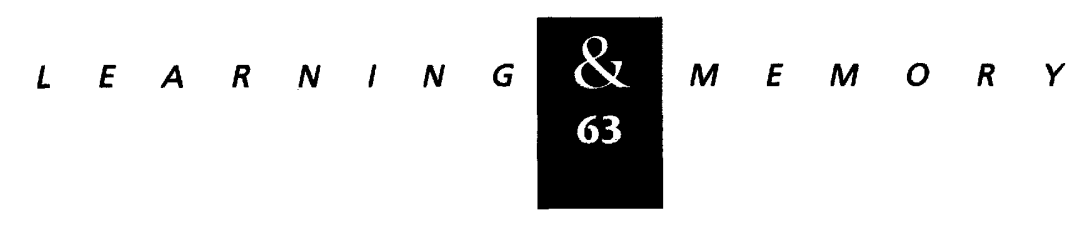


Jarvis et al.

Figure 1: Diagram showing the timing of the song and shock stimuli. (Top) An expanded sonogram (frequency vs. time) of the three-phrase song stimulus used for training; the arrow depicts the time when the shock occurred. (Bottom) Three consecutive trials. The solid bars at the beginning of each 30-sec window represent the 10 -sec resting intervals during which no stimulus was presented. The presentation of song paired with shock occurred at a random time within the next $20-\mathrm{sec}$ interval.

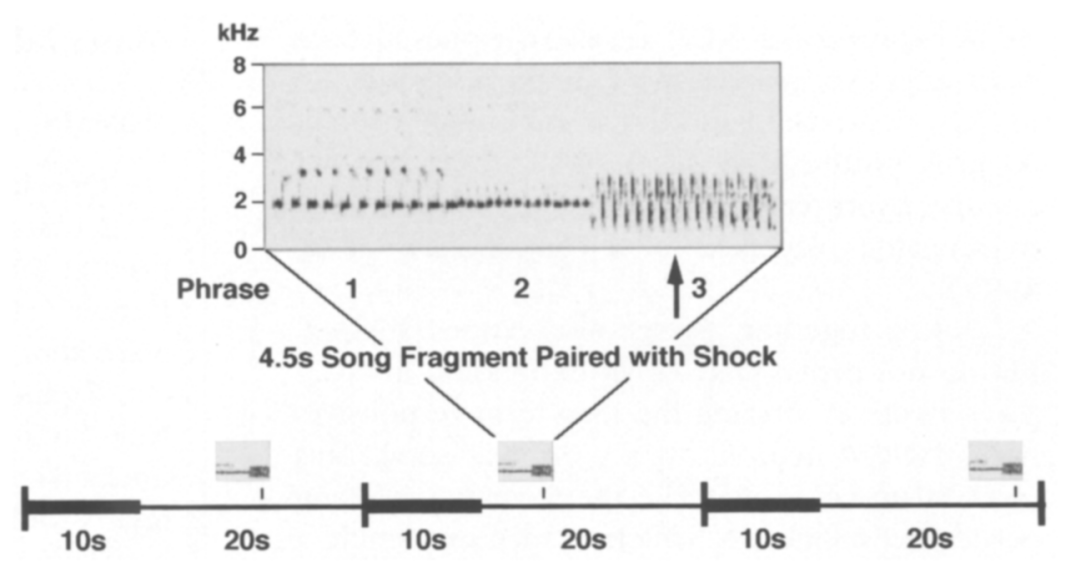

that $Z E N K$ expression is transient and peaks 30-40 min after the beginning of song playbacks (Mello and Clayton 1994) and shock avoidance can be learned during this time. Within a session, successive 30-sec periods of time started with $10 \mathrm{sec}$ of rest. Song was presented at a random time during the next $20 \mathrm{sec}$, and each presentation constituted a trial (Fig. 1). The reason for the random timing was to prevent a bird from learning to avoid the shock just by jumping at fixed intervals instead of paying attention to the song. All control animals that received song and/or shock stimuli had the same 10-sec resting interval and were exposed to a random timing of stimulus presentation.

Acquisition of the learned behavior was assessed by breaking up the 80-trial session into eight consecutive blocks of 10 trials each and scoring the percent of fear or of avoidance responses within each block. For example, if a bird jumped in response to the song during five of the trials between trials 51 and 60 and showed fear responses during three other trials, that block received a score of $50 \%$ avoidance and $30 \%$ fear responses. Fear responses were scored only for those trials in which an avoidance response did not occur and were used as an additional measure of whether an association between song and shock was learned. Occasionally, a bird was startled by the very first presentation of song and froze or jumped without having received any shock. This fear or avoidance response was counted, nonetheless, with other responses that the bird might have given during the first 10 trials.

\section{COMPUTER AUTOMATION}

To reduce experimenter bias, birds in all experiments were trained by an automated training program, BIRDHOPPER. The program runs on a Macintosh computer and was developed with the assistance of Mike Chen and Greg Tomoian from the Rockefeller University Electronics Department and is available upon request. The program delivered the song through a speaker placed under the training box, over a frequency band of up to 20 $\mathbf{k H z}$ at a mean amplitude of 80 decibels (dB). The same program delivered the shock stimulus through the metal bar floor. Infrared detectors situated to one side of the box at the height of the bird's abdomen monitored light from a 20-inchlong incandescent lamp at the other side of the box. When a bird jumped or hovered off the floor, all detectors received light, which the computer scored as a "jump." The program also scored the bird's intertrial jumps and the timing of these jumps as well as the timing of each trial. Fear responses were recorded manually from behind a one-way glass mirror.

\section{EXPERIMENTAL GROUPS}

Four experiments were done using the above apparatus and training program. One bird per group in each experiment was "trained" on any given day. Training times were balanced to avoid systematic differences in the time of day each group was run. All experiments were done between 8 a.m. and 4 p.m.

\section{EXPERIMENT 1}

This experiment was done to determine the behavior and subsequent levels of ZENK gene expression in birds presented with paired song and shock compared with the effects of presenting

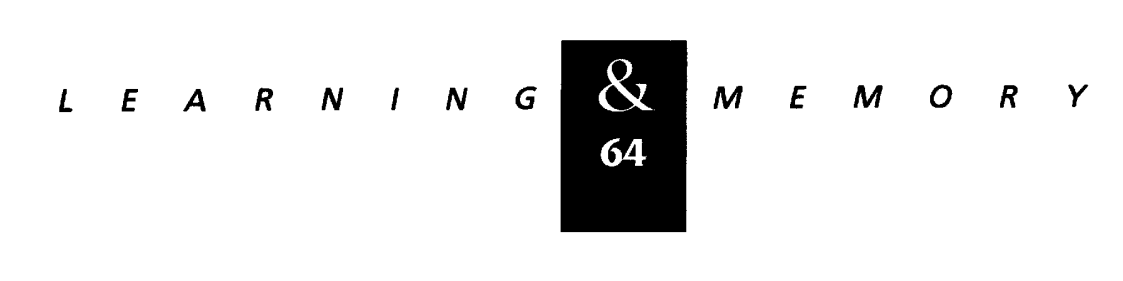


these stimuli alone or in an unpaired manner. To habituate the birds to the new environment and minimize any change in ZENK expression that might be triggered by the novelty of the box itself or by handling, birds were placed singly in the plexiglass training box $30 \mathrm{~min}$ per day for 4 days before the 40-min training or control sessions on day 5. This experiment included the following groups:

1. Quiet Controls. Birds were placed in the box and exposed just to silence $(n=6)$.

2. Paired Song and Shock. Birds were presented with song paired with shock as described above. Each bird in this group $(n=8$, slow learners; $n=8$, fast learners; see Results) was matched with a control bird from groups 4 and 5 below.

3. Song Only. Birds were placed in the box and exposed to exactly the same number of song stimuli as were group 2 birds $(n=6)$.

4. Shock Only. Each bird in this group was a matched control for one bird in group 2 and received the same schedule of shocks as that bird-more shock for controls of slow learners than for controls of fast learners $(n=8$ matched to slow learners; $n=8$ matched to fast learners).

5. Unpaired Song and Shock. Each bird in this group was a matched, yoked control for one bird in group 2 and was exposed to the same amount of song and shock as that bird, but the two stimuli in this case were delivered in a random, unpaired manner during the last 20 sec of each 30-sec period of time. Because the timing of each of the two stimuli was randomly determined, on occasion the two stimuli were paired, but most of the time $(>80 \%)$ they were not ( $n=8$ matched to slow learners; $n=8$ matched to fast learners).

\section{EXPERIMENT 2}

This experiment was done to (1) compare the long-term performance of slow learners versus that of their unpaired controls, and (2) to test the long-term memory of birds that had gone through a single training session.

1. Paired/Paired ( 5 days). Birds that were presented with song paired with shock during a 40-min session on day 1 and that were judged, from their behavior, to be slow learners were returned to their home cage for a period of 4 days. They were presented with the same pairing of stimuli on day 5 ( $n=7$ slow learners).

2. Unpaired/Paired. Matched controls to four of the seven birds in group 1 were presented with unpaired song and shock on the first session, returned to the home cage for a period of 4 days, and then presented with song paired with shock on day 5.

3. Paired/Paired ( 3 month). Birds in this group followed the same protocol as those in group 1, except that the interval between the two sessions was 3 months instead of 5 days $(n=4$ slow learners; $n=1$ fast learner).

\section{EXPERIMENT 3}

This experiment was done to compare ZENK expression in birds learning an avoidance response to a familiar or unfamiliar song for the first time with that of birds maintaining their proficiency in this same avoidance response or that had learned to give the avoidance response but now found that shock no longer followed song. Birds in this experiment had one 40-min session each day for $\mathbf{5}$ days, as follows:

1. Quiet Controls. Birds were placed in the box each day for $\mathbf{5}$ days and exposed just to silence $(n=6)$.

2. Novel Song. Birds were exposed to silence for 4 days and then to a novel song on day 5 , in the same manner as those presented with song in group 3 of experiment $1(n=6)$.

3. Novel Song Paired with Shock. Birds were exposed to silence for 4 days and then presented with song paired with shock on day 5 in the same manner as those trained in group 2 of experiment 1 ( $n=5$ slow learners; $n=1$ fast learner).

4. Familiar Song (Habituation). Birds were presented with the same song each day for 5 days $(n=6)$.

5. Familiar Song Paired with Shock (Dishabituation). Birds were presented with the same song for 4 days, and on day 5 this song was paired with shock ( $n=5$ slow learners; $n=1$ fast learner).

6. Overtraining. Birds were presented with the same song paired with shock each day for 5 days $(n=7)$

7. Extinction. Birds were presented with the same

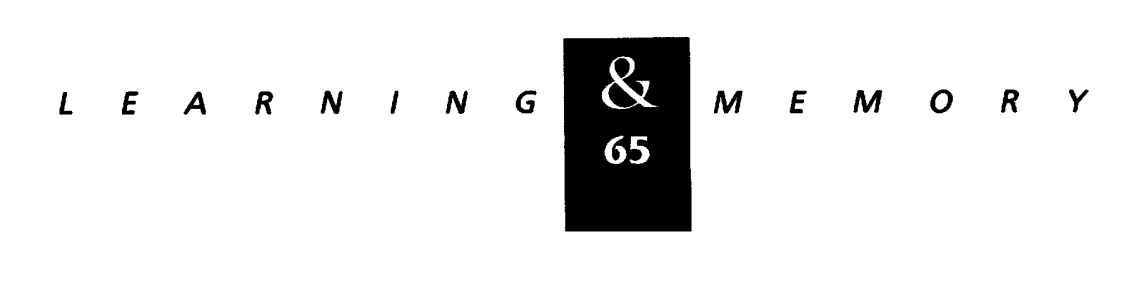


Jarvis et al.

song paired with shock each day for 4 days. On day 5 the shock was removed, and they were presented just with the familiar song $(n=7)$.

\section{EXPERIMENT 4}

To determine whether further training had any effects on ZENK expression, birds in this experiment were trained as those of groups 1,4 , and 6 in experiment 3, but for a 10-day instead of a 5-day period.

1. Quiet Control, 10 days; $n=4$.

2. Familiar Song, 10 days; $n=5$.

3. Overtraining, 10 days; $n=5$.

\section{IN SITU HYBRIDIZATION AND QUANTITATIVE ANALYSIS}

In situ hybridizations were performed with the brains of animals in experiments 1,2 , and 4 using the protocol described in Mello and Clayton (1995), with the following modifications. Birds were decapitated immediately after the end of the last 40-min session. Brains were quickly dissected and frozen; $10-\mu \mathrm{m}$ sections were cut in a cryostat in the parasagittal plane up to $3 \mathrm{~mm}$ from the midline to ensure inclusion of the song nuclei HVC (high vocal center), RA (robust nucleus of the archistriatum), IMAN (lateral portion of the magnocellular nucleus of the anterior neostriatum), and area $\mathrm{X}$ of the lobus parolfactorius (Nottebohm et al. 1976, 1982). Sections were stored at $-70^{\circ} \mathrm{C}$. On the day of hybridization sections were fixed in 3\% paraformaldehyde at room temperature. Every twentieth section was hybridized with ${ }^{35}$ S-labeled antisense riboprobes from the canary ZENK CDNA. Adjacent sections were hybridized with riboprobes from the canary HAT2 cDNA. HAT2 mRNA is enriched in the forebrain (George and Clayton 1992) but is not regulated within $40 \mathrm{~min}$ of song presentation or shock (see Results) and therefore serves as a control for the specificity of the $Z E N K$ response. In addition, at least one brain section from each experiment was hybridized to the ZENK sense strand as a control for antisense specificity. Sections were exposed, along with Amersham ${ }^{14} \mathrm{C}$ labeled radioactive standards, to Amersham B-max Hyperfilm for 2-4 (ZENK) or 1-2 (HAT2) weeks.

Variability due to procedural differences was minimized by fixing and hybridizing all sections from a given anatomical plane at the same time.
Optical density (OD) values for each anatomical region were measured and averaged for two adjacent sections using Wayne Rasband's Macintoshbased image processing and analysis software (NIMH Image). The OD measurement represents an average density value for the entire area scanned. All values fell within the linear range of the radioactive standards exposed with the slides. After subtracting the background (film density over the glass slide), the OD values for all groups in each of the areas measured were divided by the average value for the quiet control group in that area, to get a normalized scale where quiet control $=1$.

\section{STATISTICS}

The data in this paper are of two types: (1) behavioral performance expressed as a percentage of shocks avoided, and (2) OD measurements of in situ hybridizations. Although the OD was collected within a linear range, there is no guarantee that the OD value bears a linear relationship to the amount of mRNA gene expression. Because in both cases, the assumptions of normality and homoscedasticity (i.e., having the same variance) could not be verified, it was decided to use nonparametric statistics.

The Mann-Whitney U-test (two-tailed probabilities, criterion for significance of $P<0.05$ ) was used to determine the statistical significance of differences in behavioral performance and/or ZENK expression between nonmatched groups as when comparing the paired song and shock vs. quiet control groups. The Wilcoxon matched pair signed-ranks test (two-tailed probabilities, criterion of $P<0.05$ ) was used to test for differences between matched groups (Siegel 1956) as when comparing birds in the paired song and shock groups with their matched yoked-unpaired controls. In groups where $n<6$, the Wilcoxon's signed-ranks test is not valid (Sokal and Rohlf 1969) and the Mann-Whitney U-test was used instead. The number of avoidance or fear responses in each of the eight blocks of 10 trials was used for behavioral comparisons. For each of the eight blocks, $\boldsymbol{P}$ values were calculated for comparison between different groups. The $P$ values presented in the behavior section below are for the very first block that showed a significant difference. The Kendall rank correlation test (criterion of $P<0.05$ ) was used to test for significance of correlations of

$$
\begin{array}{llllllllllllllll}
\mathcal{Q} & E & A & R & N & I & N & G & M & E & M & O & R & Y \\
66 & & & & & & & & &
\end{array}
$$


behavioral performance with the levels of gene expression within that group.

\section{Results}

PART I, BEHAVIOR

LEARNING OF THE AVOIDANCE RESPONSE, EXPERIMENTS 1 AND 2

There was great individual variability in the number of avoidance responses that birds in the paired song and shock group gave to song, but most birds tended to segregate into two groups: those that performed very well and those that performed poorly (Fig. 2). To determine whether this difference in behavioral performance corresponded to a difference in $Z E N K$ expression, these two groups were analyzed separately. Birds that avoided the shock in $40 \%$ or more of the trials during the first training session in any block of 10 trials before trial 60 were designated fast learners. The rest were designated slow learners (Fig. 2). Less than one-fifth of the birds trained in the paired song/shock paradigm were fast learners, and many birds had to be trained before we had a

\section{A FAST LEARNERS}
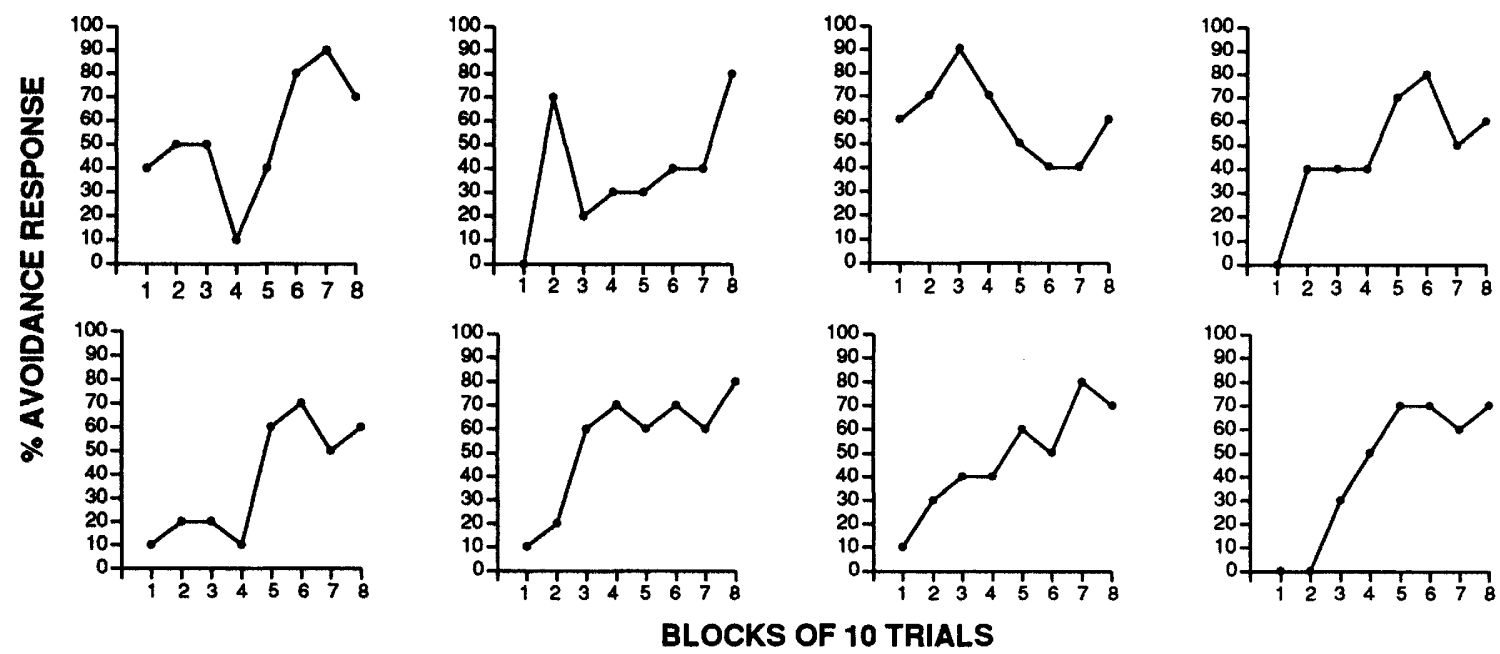

\section{B SLOW LEARNERS}
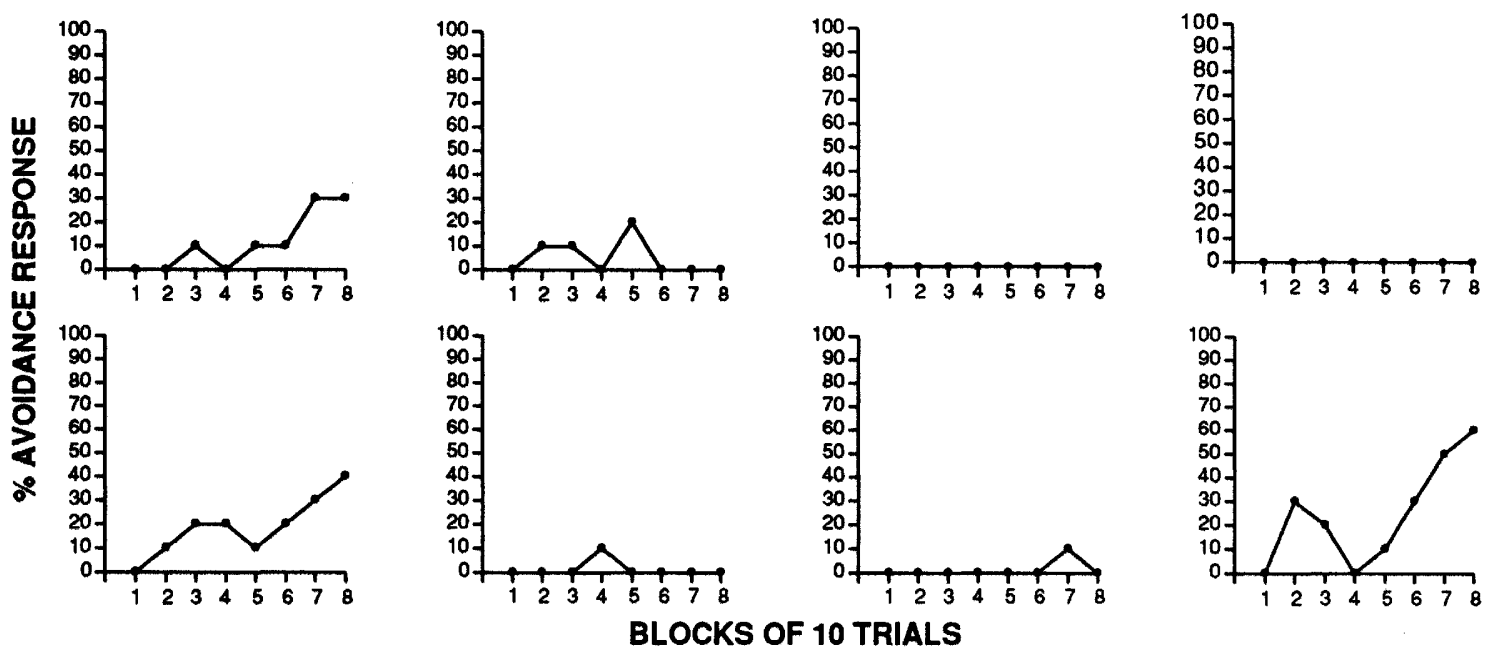

Figure 2: Avoidance response curves of individual birds from group 2 of experiment 1 trained to associate song with shock. Fast learners $(A)$ are compared with slow learners $(B)$. Plotted is the percent avoidance responses for each block of 10 trials.

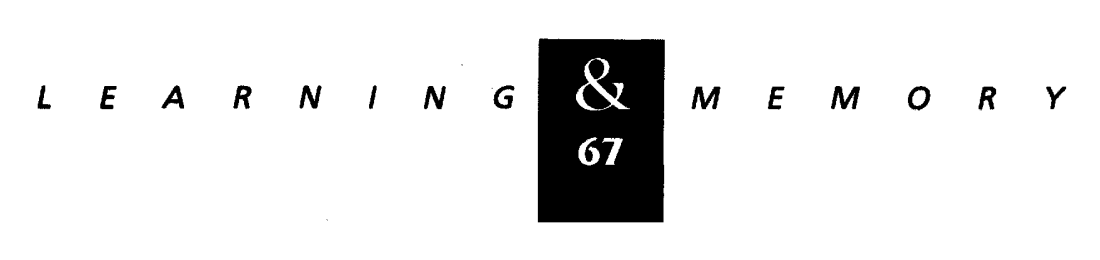


large enough sample of fast learners. By the end of the first training session (block 8), fast learners avoided the shock on an average of $70 \%$ of the trials (Fig. 3A). In contrast, some slow learners showed zero shock avoidance at the end of their first training session (Fig. 2B). The difference in performance between slow and fast learners was already apparent during the second block of trials $(P=0.01$; Fig. 3A). Control birds presented with song only seldom jumped in response to the song (Fig. 3A). The behavior of female canaries trained with this paradigm was the same as that of males (not shown).

Control birds that were presented with song and shock in a yoked-unpaired manner gave few avoidance responses to song (Fig. 3B). The response of fast learners differed significantly from that of their matched unpaired controls already during the second block of trials $(P=0.018)$. In contrast, the percent avoidance response of the slow learners did not differ significantly from that of their unpaired controls at any time during the first session $(P=0.102)$.

To assess whether or not slow learners actually learn an association between song and shock during the first session, a group of seven slow learners (Experiment 2) was tested on a second session 5 days after the first. These birds responded immediately with an average of $60 \%-$ $75 \%$ shock avoidance and maintained that level throughout the second session, suggesting that these birds had learned something during the first session (Fig. 4A). The performance during the first block of 10 trials on the second session was significantly better than during the last block of trials on the first session $(P=0.018)$ and remained high throughout the entire session. When unpaired controls $(n=4)$ of these slow learners were exposed to paired song and shock on the second session, they performed as if they were being trained on the association for the first time (three slow learners/one fast learner). The shock avoidance of these controls during the second session was significantly lower than that of the slow learners that had already been exposed to the pairing of song and shock during the previous session $(P=0.012$; Fig. 4A, right $)$.

LEARNING AND THE FEAR RESPONSE, EXPERIMENT 2

Another indication that slow learners made an association between song and shock on the first session was given by their fear responses (Fig. 4B). Slow learners gave more fear responses to song during the first training session than their matched unpaired controls; this difference was already significant by the second block of trials $(P=0.037$; Fig. $4 \mathrm{~B}$, left). On a second session 5 days later, the fear response of slow learners was still present on trials where the birds did not show the avoidance response. The unpaired controls of these birds exposed to paired song and shock during the second session, showed a percent of fear responses that was similar to that of slow learners trained on the association for the first time (compare upper curves of Fig. 4B) and was significantly higher than during their first session $(P=0.036)$.

The above results suggest that the slow learners first learned that song predicted shock and subsequently learned how to avoid the shock. Fast learners also went through an initial stage of fear responses (not shown) but were faster at making the transition from fear to avoidance responses. The unpaired groups formed no predictive association between song and shock during session 1 , as shown by the absence of fear responses to the song on session 1 and by their poor performance on session 2.

The memory of the initial association between
Figure 3: Avoidance response curves of birds in experiment 1 trained with paired or unpaired song and shock. (A) Average avoidance responses of song only controls and of fast and slow learners in the paired group (same birds as in Fig. 2). (B) Average avoidance responses of unpaired matched controls for the fast and slow learners in A. Bars represent S.E.M.

\section{A PAIRED TRAINING}

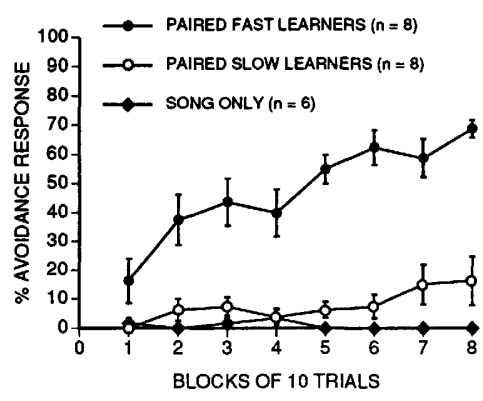

\section{B UNPAIRED TRAINING}

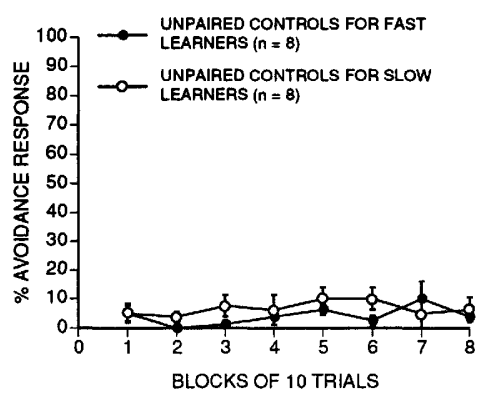

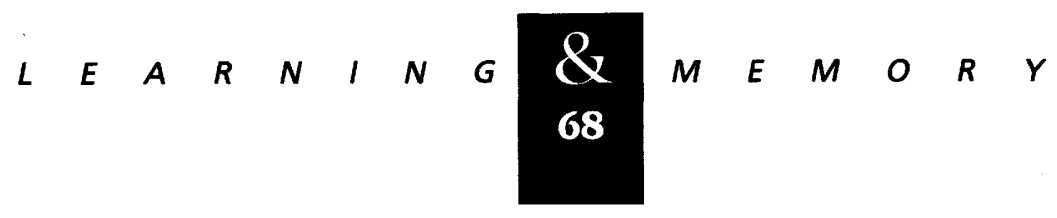




\section{A AVOIDANCE RESPONSE}
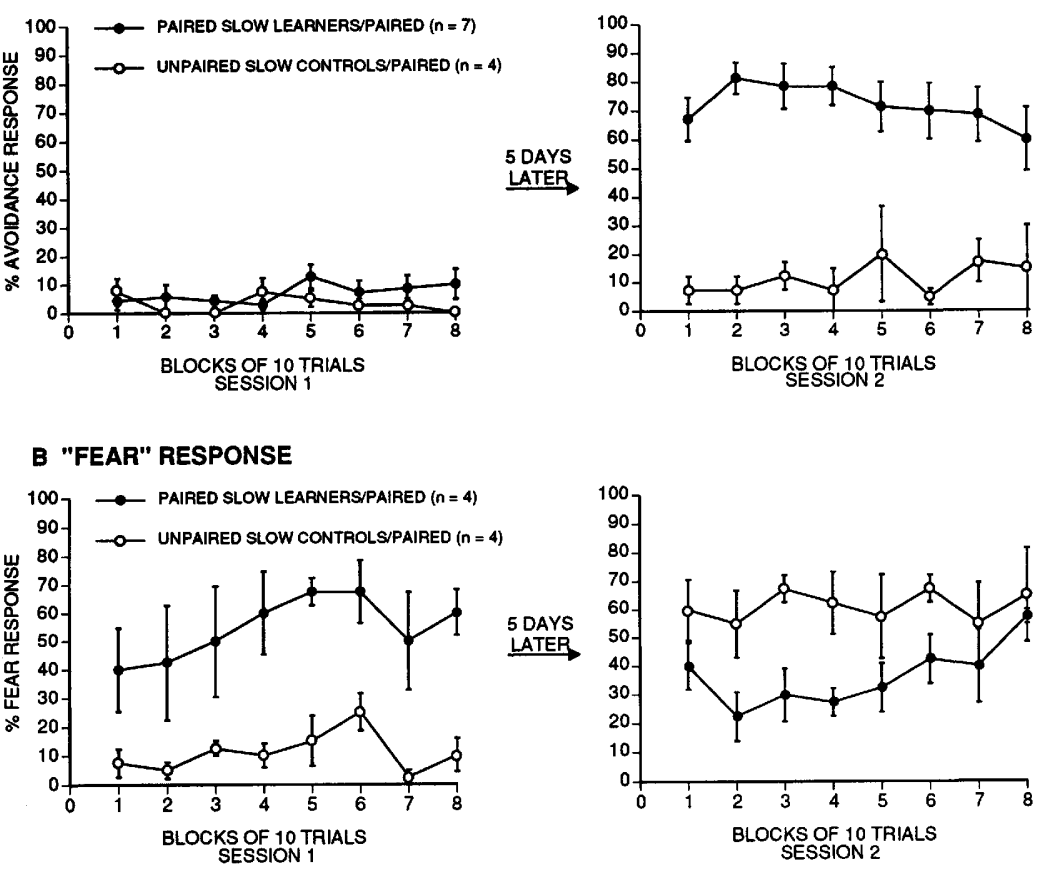

Figure 4: Avoidance and fear responses of slow learners and their matched unpaired controls in experiment 2. (A) Average avoidance response curves of slow learners during two sessions separated by 5 days compared with curves of four controls who received unpaired training on session 1 and paired training on session 2. (B) Average fear response curves for slow learners during the same sessions as in $A$. After we had put three slow learners through a first session of song paired with shock, we realized that these birds gave fear responses to the song. We then systematically quantified the fear responses of the next four slow learners and held them as representative for the whole group. Bars represent S.E.M. song and shock persisted beyond the fifth day as shown by five birds (four slow learners/one fast learner) tested 3 months after the first session (Fig. 5). Their initial performance during the second session was not significantly different from the performance at the end of session $1(P=0.75)$. The performance gradually improved and remained high throughout the rest of the session but was not as good as when a mere 5 days had elapsed (cf. Figs. 4A and 5).

OVERTRAINING, EXPERIMENTS 3 AND 4

Birds that were exposed to paired song and shock for 5 days showed a steady increase in per-

\section{LONG TERM MEMORY}
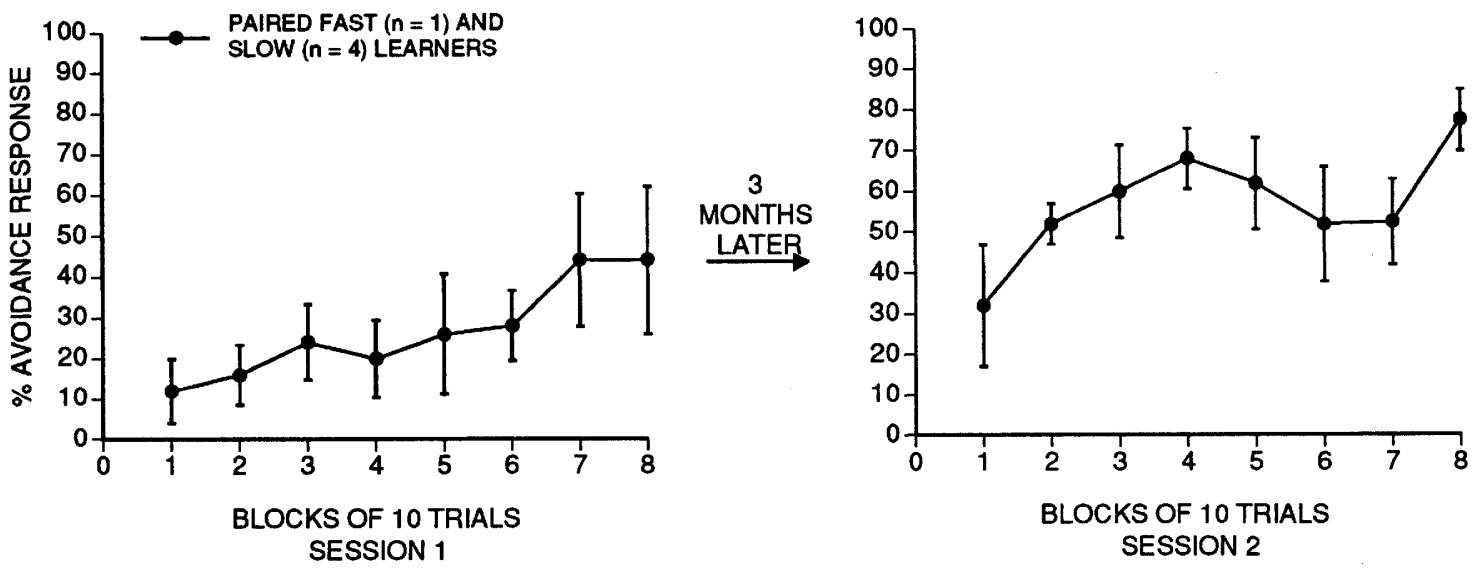

Figure 5: Long-term memory of the learned avoidance response after a single training session. The average avoidance response curves of five birds (four slow learners, one fast learner) during two training sessions separated by 3 months are shown. Bars represent S.E.M.

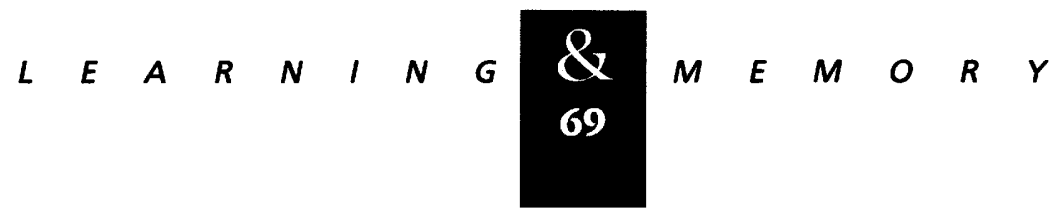


Jarvis et al.

formance until day 4, with less increase thereafter (Fig. 6A). Between the sixth and tenth session they showed an asymptotic $80 \%-100 \%$ avoidance response. This level probably represents the maximum avoidance performance obtainable in this training paradigm. An analysis was done to determine which phrase of the song stimulus elicited the avoidance response. Although the initial response was mostly to the first phrase, during the progress of overtraining, the birds avoided the oncoming shock more and more often by jumping to the third phrase of the song stimulus (Fig. 6B), just before the shock was due to occur (Fig. 1).
EXTINCTION OF THE AVOIDANCE RESPONSE, EXPERIMENT 3

The incidence of the avoidance response was reduced markedly when, after 4 days of training with the conditioning paradigm, shock was discontinued and song was presented alone on day 5 (Fig. 7). This extinction of the avoidance response usually occurred over a few trials after one trial in which the bird did not jump and failed to experience shock. The difference in the avoidance response between birds still exposed to paired song and shock (overtraining group) and those in

A OVERTRAINING / 10 DAYS

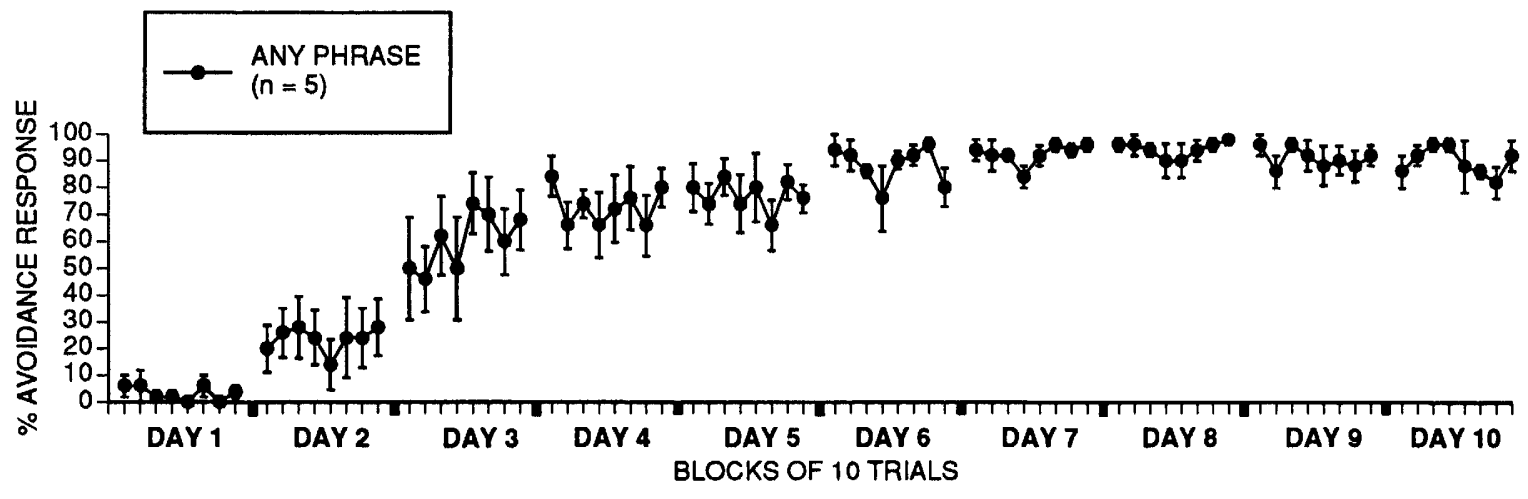

B PHRASE JUMPED ON

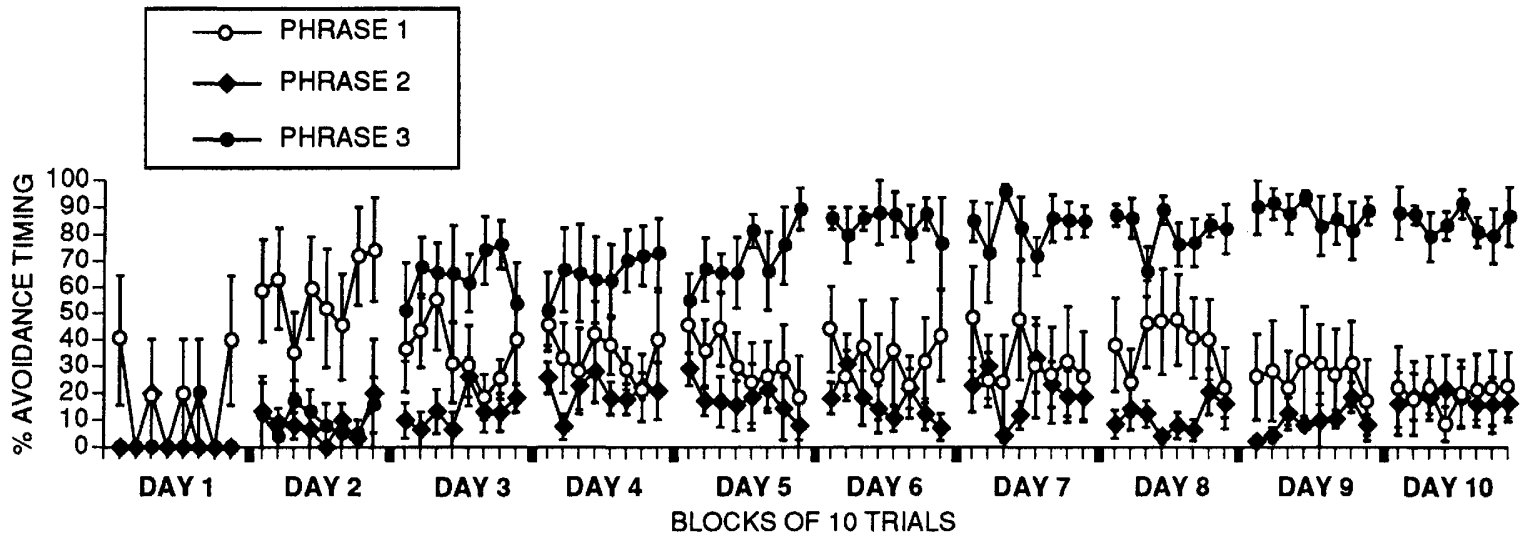

Figure 6: (A) Avoidance responses during 10 successive training sessions of paired song and shock (overtraining group of experiment 4). (B) Avoidance jump timing of the same birds during the same sessions as in $A$. Each value represents the percent of the total avoidance responses that the bird made on one of the three song phrases shown in Fig. 1. Because birds sometimes jumped more than once to a song, the values for each phrase are not additive. The overall avoidance performance did not improve noticeably after day 6 ; however, there was refinement in the timing of the avoidance response to the third phrase of the song even after day 6 . Thick lines on the $x$-axis represent $23-\mathrm{hr}$ intervals between training sessions. Bars represent S.E.M.

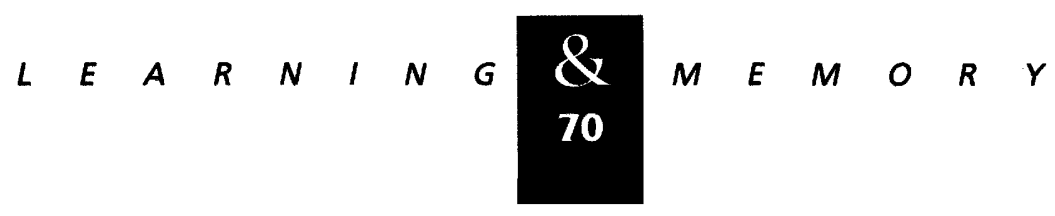




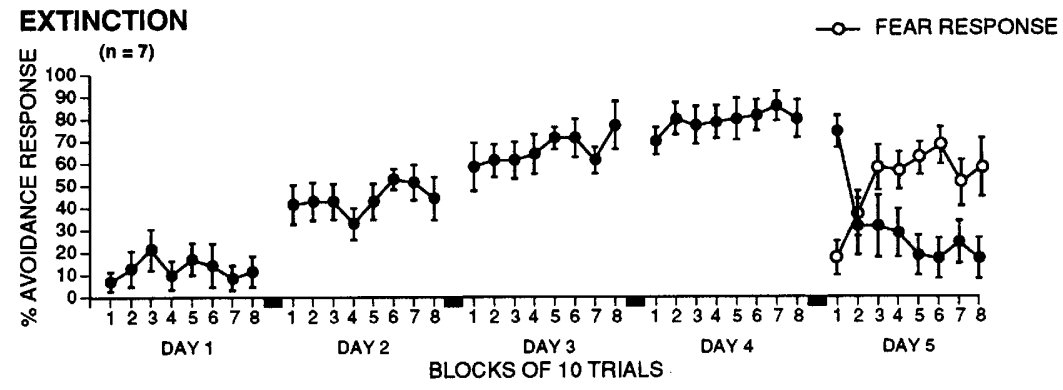

Figure 7: Average avoidance response curve of birds in the extinction group. Shock was discontinued on the fifth session, creating the conditions for extinction of the response. Fear responses (shown only for the last session) reappeared during extinction. Thick lines on the $x$-axis represent $23-h r$ intervals between training sessions. Bars represent S.E.M. which the response was extinguished was significant from trial 20 onward $(P=0.011)$ on day 5 . As the avoidance response disappeared, the fear response reappeared (Fig. 7).

\section{SUMMARY OF PART I}

The above results demonstrate that birds can be trained to associate song with an aversive stimulus (shock), and this learning has the characteristics described for conditioning in other species (Pavlov 1927; for review, see Schwartz 1984; LeDoux 1995). Although both freezing and flight are part of the natural defense response repertoire of birds (Edmunds 1974; Marks 1987), it appears that conditioned fear to a song stimulus induces freezing more readily than flight. The transition from fear to an avoidance response is learned more slowly by the majority of birds, when compared, for instance, with rats trained in a shuttle box to avoid a shock in response to a tone (Kamin 1956). In contrast, canaries extinguished their avoidance responses more quickly than what has been seen with rats (Schwartz 1984). These differences could result from species-specific differences in learning or to the different physical tasks required.

To determine whether or not a correlation exists between changes in IEG expression and associative learning, different training protocols and various manipulations of the stimuli were performed. The song only and shock only groups control for the effects of presenting each stimulus alone. Shock alone is expected to result in a level of stress comparable to, if not greater than, that of the paired trained group (Weiss 1970, 1977). The yoked-unpaired group serves as a nonassociative control (Rescorla 1969; Rescorla and Wagner 1972). The overtraining groups serve as nonlearning controls that still must pay attention to the song to avoid shock; and the extinction (Bouton and Swartzentruber 1991) and dishabituation groups are expected to learn something new about the song. The results below present the findings on the levels of expression of the IEG ZENK in the several groups studied.

\section{PART II, GENE EXPRESSION}

CONDITIONING, EXPERIMENT 1

In situ hybridization autoradiographs of representative birds from experiment 1 are shown in Figure 8. The results of the quantitative analysis are shown in Figure 9. Quiet control canaries showed low but detectable levels of ZENK expression in several regions of the medial forebrain, including hippocampus ( $\mathrm{Hp}$ ), hyperstriatum ventrale (HV), hyperstriatum accessorium (HA), parts of rostral neostriatum (N), septum (S) and lobus parolfactorius (LPO). This expression was higher than that seen in birds isolated for a day in soundproof chambers (not shown; see Mello et al. 1992). Prehabituation of the birds to the training box did minimize but was not sufficient to eliminate basal $Z E N K$ expression because of handling. ZENK levels in NCM and the adjacent HVCM were lower than the rest of the forebrain (Fig. 8). Because the latter two areas behave in a similar manner and are both presumably involved in auditory processing (see below; Mello and Clayton 1994), they will be treated from here on as one unit, the NCM-HVCM region.

Playbacks of the song fragment shown in Figure 1 induced a threefold increase of ZENK mRNA levels in NCM-HVCM of the song only group when compared with quiet controls $(P=0.004)$; no induction was seen in other regions of the medial forebrain (Figs. 8 and 9A,B). Shock alone induced ZENK expression in medial Hp, HV, HA, N, S, and LPO (see Fig. 8) when compared with quiet controls, with the most robust effect being a 2.3-

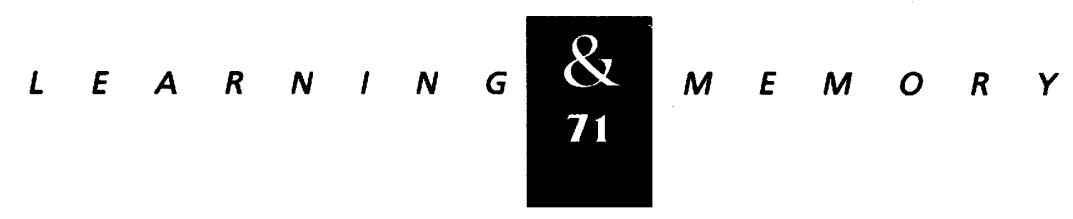


Jarvis et al.

Figure 8: In situ hybridization autoradiographs of parasagittal brain sections of trained and control birds from experiment 1, hybridized with ZENK riboprobes. Shown are medial sections (200 $\mu \mathrm{m}$ from midline) of birds representing the average ZENK level in their corresponding groups. The shock only (top) and unpaired (bottom) birds are the individual matched controls for paired fast and slow learners (middle). The schematic diagram (lower left) shows the anatomical regions where OD measurements were taken: $(\mathrm{Cb})$ cerebellum; (HA) hyperstriatum accessorium; $(\mathrm{Hp})$ hippocampus; (HV) hyperstriatum ventrale; (HVCM) caudomedial hyperstriatum ventrale; (LPO) lobus parolfactorius; (N) rostral neostriatum; (NCM) caudomedial neostriatum; (S) septum. NCMHVCM appears as a pear-shaped structure where ZENK induction by song is enhanced when the song is paired with shock. Shock-induced ZENK expression in other brain areas is not enhanced by its pairing with song.
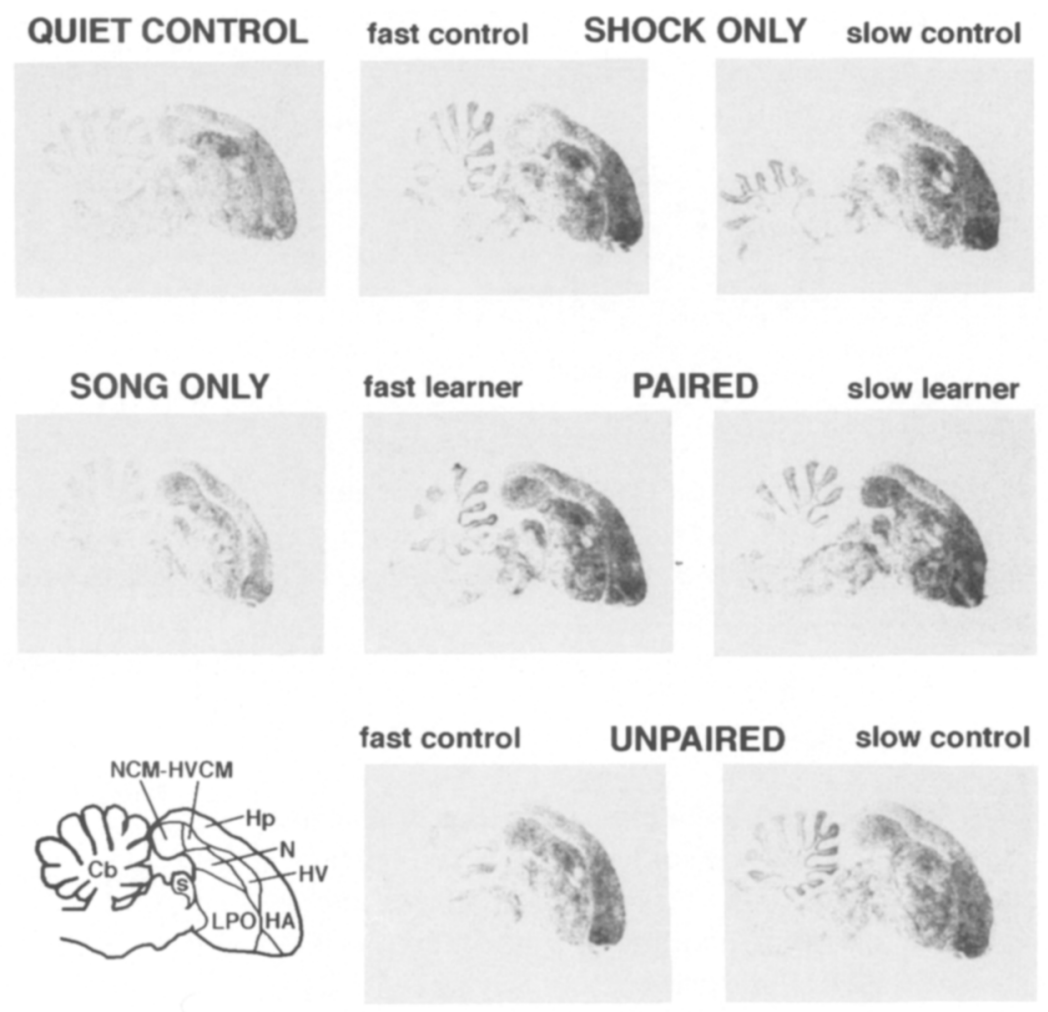

fold increase in rostromedial HA $(P=0.002$; Fig. 9B); no significant induction was seen in NCMHVCM. significant shock-induced ZENK expression was also seen in lateral regions of HA and HV, and in the periectostriatum, but not in the ventrolateral forebrain (not shown).

Canaries in the paired and unpaired song and shock groups (Fig. 3) showed ZENK induction in the same regions where it was induced by either song or shock alone (Fig. 8). However, ZENK expression in NCM-HVCM of the paired groups was higher than that seen in the unpaired controls, which was comparable to the song only group (see Fig. 9A). This enhancement was about twofold higher for slow learners than for fast learners. ZENK levels were 43\% higher in slow learners and $21 \%$ higher in fast learners than in their matched unpaired controls [see Fig. 9 legend for details and statistics]. No significant differences in ZENK expression were seen between paired and unpaired groups in the other regions quantified (see Fig. 9B for quantitation of the HA region).

ZENK expression in the cerebellum was variable but not related to the stimulus conditions of any one group (Figs. 8 and 9C). Induction of ZENK expression in NCM-HVCM by song or by song paired with shock was not accompanied by a gen- eralized change in gene expression. HAT2 (George and Clayton 1992) remained the same under all behavioral conditions tested (Fig. 9D). No regulated ZENK expression was seen in the song control nuclei HVC, RA, IMAN, or area $X$ that correlated with any of the behavioral conditions tested. However, $>40 \%$ of birds tested in the fall had enriched $Z E N K$ expression in HVC, RA, and IMAN (not shown) a time when many adult male canaries show marked seasonal song plasticity (E. Jarvis and F. Nottebohm, in prep.).

\section{OVERTRAINING, EXPERIMENTS 3 AND 4}

The quantitative analysis of ZENK gene expression in the overtraining groups of experiments 3 and 4 are shown in Figure 10. As in experiment 1 , presentation of a novel song induced a threefold increase in ZENK expression in NCM-HVCM compared to quiet controls $(P=0.004)$. Birds presented with paired song and shock for the first time showed levels of $Z E N K$ expression that were 4.8-fold higher than in quiet controls $(P=0.004)$. Birds exposed to paired song and shock for 5 consecutive days (overtraining group of experiment 3), showed one-third less ZENK expression in

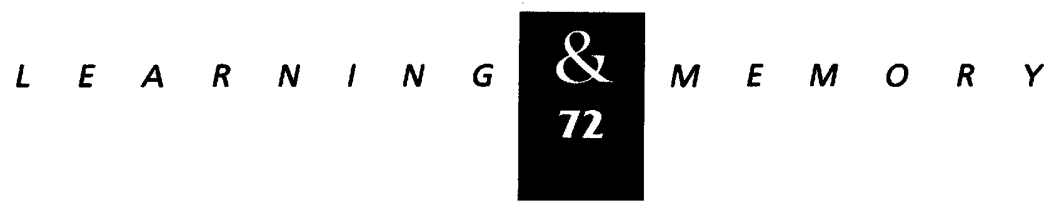



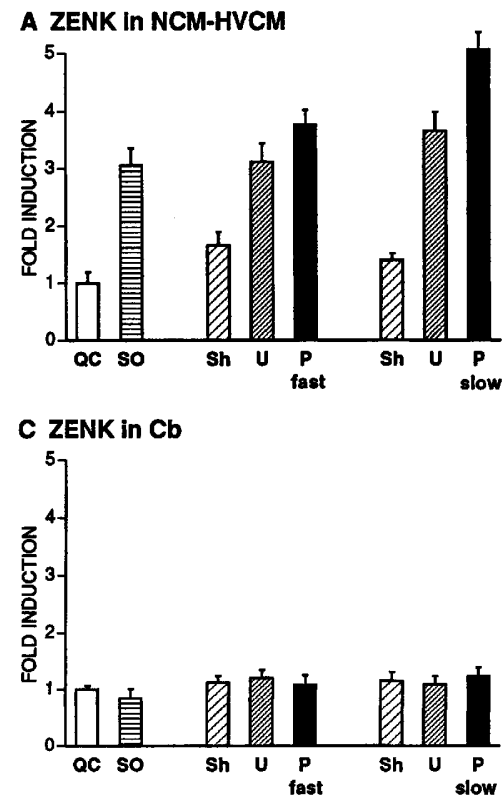
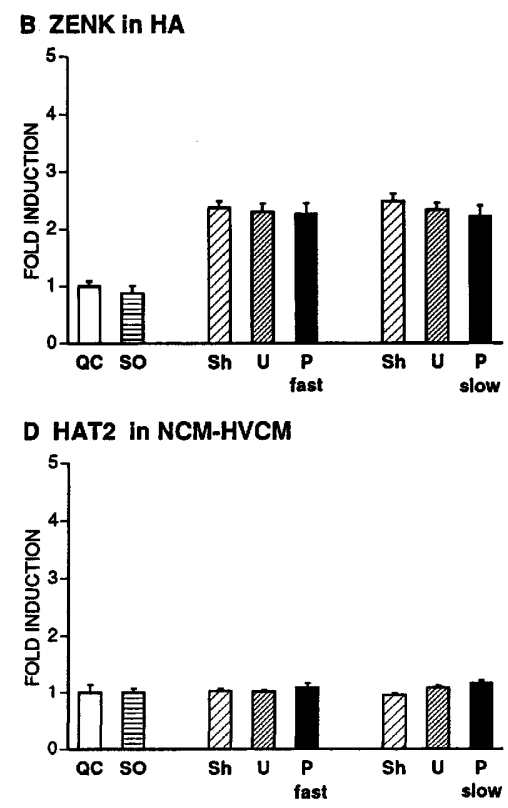

Figure 9: Quantitative analysis of ZENK and HAT2 expression in medial parasagittal brain sections (same level as in Fig. 8) of trained and control animals from experiment 1 . For each region, all optical density values were divided by the quiet control value to create a normalized ZENK fold-induction scale. Columns represent the mean normalized value for each group, and the error bars represent S.E.M. The groups shown are $(\mathrm{QC})$ quiet control; (SO) song only; (Sh) shock only; $(P)$ paired song and shock; and (U) unpaired song and shock. (Cb) Cerebellum; (HA) hyperstriatum accessorium; (HVCM) caudomedial hyperstriatum ventrale; (NCM) caudomedial neostriatum. Different statistical analysis were applied for different comparisons, depending on whether or not the comparisons were between matched groups (see Materials and methods). In the NCM-HVCM region $(A)$,

song only induced ZENK mRNA levels threefold above quiet controls ( $P=0.004$; Mann-Whitney U-test). Shock only birds showed a small but nonsignificant ( $P \geqslant 0.09$; Mann-Whitney U-test) increase over quiet controls. However, ZENK expression in NCM-HVMC was enhanced in the paired groups. Fast learners showed a small, but significant, increase in ZENK expression above their matched yoked-unpaired controls ( $P=0.05$; Wilcoxon signed ranks test). However, this increase was not significant under the less stringent comparison with the song only group $(P=0.121 \mathrm{Mann}-\mathrm{Whitney}$ U-test). Slow learners showed a larger, 1.5-fold enhancement above their matched yoked-unpaired controls $(P=0.036$; Wilcoxon signed ranks test) as well as a 1.7 -fold enhancement above the song only group $(P=0.003 ;$ Mann-Whitney U-test).

NCM-HVCM than birds exposed to a novel song paired with shock for the first time $(P=0.005)$. Birds trained for a period of 10 days (experiment 4) showed lower levels of ZENK expression in NCM-HVCM than those trained for 5 days $(P=0.028)$. However, these reduced levels in the overtraining groups were still higher than those seen in quiet controls $(P=0.014)$. Birds habituated to song during the same periods also showed less and less ZENK expression in NCM-HVCM after 5 and 10 sessions. This expression was also significantly higher than levels in quiet controls $(P<0.05)$ but below the levels in birds trained with song paired with shock for 5 and 10 days $(P<0.047)$.

\section{DISHABITUATION, EXPERIMENT 3}

As mentioned above, birds that heard a particular song 4 days in a row and the same song on day 5 (familiar song) showed a drop of $26 \%$ in the induced expression of ZENK in NCM-HVCM compared with that seen in birds that heard this song for the first time (novel song; $P=0.045$ ). This drop in $Z E N K$ expression was prevented if the familiar song was paired with shock on day $5(P=0.025$, Fig. 11A). However, ZENK levels in this dishabituation group were significantly lower than those seen in birds exposed to a novel song paired with shock $(P=0.045)$ suggesting that song novelty and the novelty of pairing that song with shock affected $Z E N K$ expression in an additive manner.

\section{EXTINCTION, EXPERIMENT 3}

Birds in the extinction group (Fig. 7) showed levels of ZENK expression in NCM-HVCM that, as a group, were not different from the overtraining group (Fig. 11A). However, a correlation analysis showed that those birds that extinguished their avoidance response the fastest had the lowest ZENK expression levels and those that extinguished the slowest had higher ZENK levels $(\tau=0.619, P=0.051)$ (Fig. 12B). Interestingly, the correlation curve intersected the $y$-axis at 1.8 -fold, which is close to the level (2-fold) induced by hearing familiar song alone on day 5 (Fig. 11A). This result and the relatively high $\tau$ value encour-

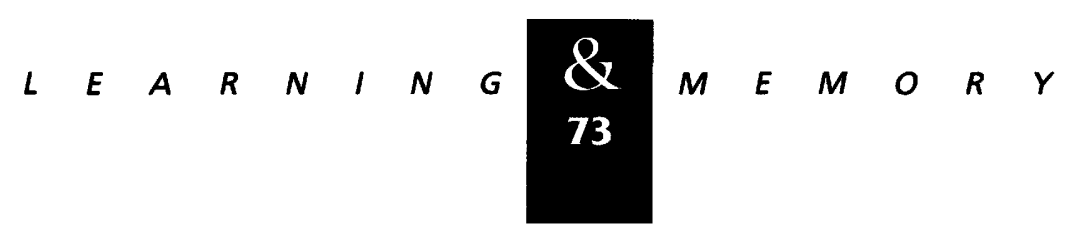




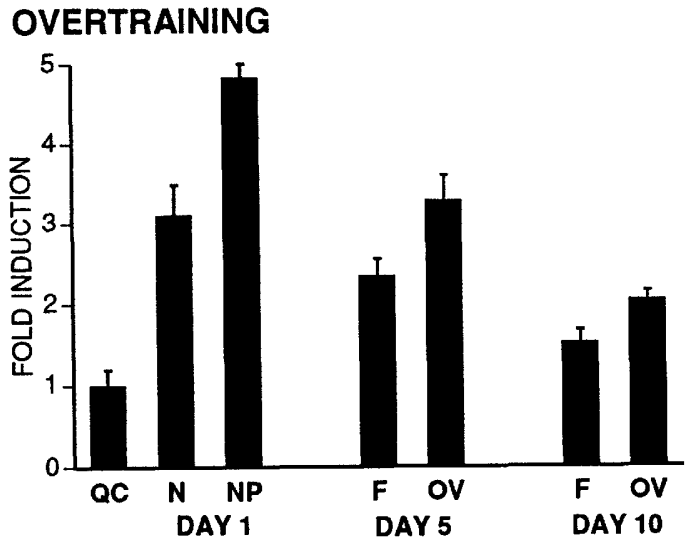

Figure 10: Quantitative analysis of ZENK expression in medial parasagittal sections (same level as in Fig. 8) of the NCM-HVCM region of birds in the overtraining groups and their controls from experiments 3 and 4 . For each region, all $O D$ values were divided by the quiet control value to create a normalized ZENK fold-induction scale. Columns represent the mean normalized value for each group, and the error bars represent S.E.M. The groups shown are $(\mathrm{QC})$ quiet control of experiment 3; (N) novel song only; (NP) novel song paired with shock; (F) familiar song (habituation); (OV) overtraining with familiar song paired with shock. With successive training sessions (day 1, 5, and 10) induced ZENK expression drops. For statistical analysis, see Results.

age us to believe that the correlation is real, even if the $P$ value, perhaps because of a small sample size, is slightly above our criterion for significance.

As in experiment 1 , the differences of $Z E N K$ expression in NCM-HVCM among the various groups were not accompanied by corresponding differences in HAT2 expression levels (Fig. 11C). The levels of ZENK expression in HA were influenced by experience with the shock. The two groups that showed the highest levels of ZENK expression in HA (shock paired with novel or familiar song) were also the two groups that received the greatest number of shocks (Fig. 11B).

Combining data from all birds in the paired groups of experiments 1 and $3(n=22)$ and then performing a correlation analysis between the number of shocks paired with song (those trials in which the birds failed to jump to the song) and the resulting levels of $Z E N K$ expression yielded additional insight into how ZENK expression is regulated in NCM-HVCM. There was a significant positive correlation between $Z E N K$ expression in NCM-HVCM and the number of times song was paired with shock $(\tau=0.304, P=0.048$; Fig. 12A $)$.
The number of pairings was smaller for fast learners than for slow learners because the former gave more avoidance responses. This regression also has predictive value. The $y$-intercept at 2.87 is comparable to the threefold induction by novel song in the absence of shock (see song only groups in Figs. 9A and 10A).

\section{LATERALITY}

Intriguingly the combined data discussed in the previous paragraph also revealed that $Z E N K$ expression was on average $25 \%$ higher in the right than in the left NCM-HVCM of birds that were exposed to paired song and shock $(P<0.001$, $n=22$ ). All of our graphs show the right-side levels of ZENK expression. There were no significant right versus left differences in the birds exposed to song alone.

\section{Discussion}

A growing number of studies have begun to analyze the relation between IEG expression and learning both in the avian (Anokhin et al. 1991; Anokhin and Rose 1991; McCabe and Horn 1994) and rodent brains (Maleeva et al. 1989; Tischmeyer et al. 1990; Campeau et al. 1991; Bailey et al. 1992; Brennan et al. 1992; Nikolaev et al. 1992a,b; Smith et al 1992; Heurteaux et al. 1993; Fordyce et al. 1994; Paylor et al. 1994). In those studies expression of IEGs increased in parts of the brain soon after animals underwent behavioral training. Such observations have been used to support the hypothesis that IEGs play a role in learning in vertebrates (for review, see Rose 1991; Kaczarek 1993).

It is well known that the time relationship between CS and US is important for associative learning (Pavlov 1927; Rescorla and Wagner 1972). In studies attempting to establish a correlation between associative learning and gene expression in the brain, it is essential to control for the effects of presenting each stimulus alone or in an unpaired manner and to evaluate the contribution of factors such as stimulus novelty, stress, and attention. In the present study, the expression of the ZENK gene in the brain of adult male canaries engaged in associative learning was investigated and an attempt was made to control for the effect of each of the above factors.

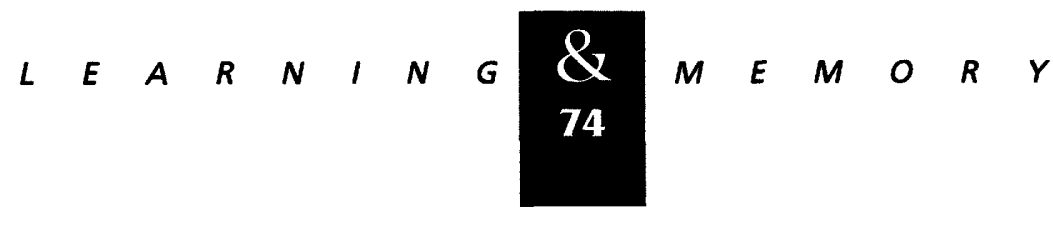


A ZENK in NCM-HVCM

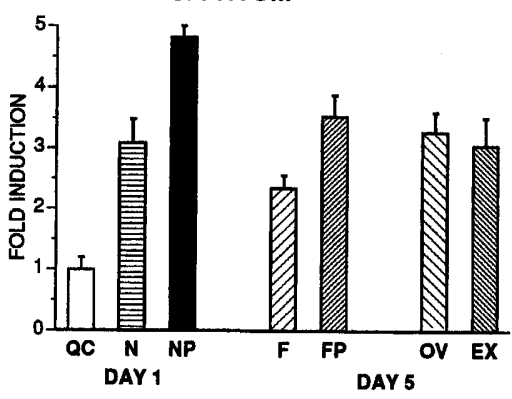

B ZENK in HA

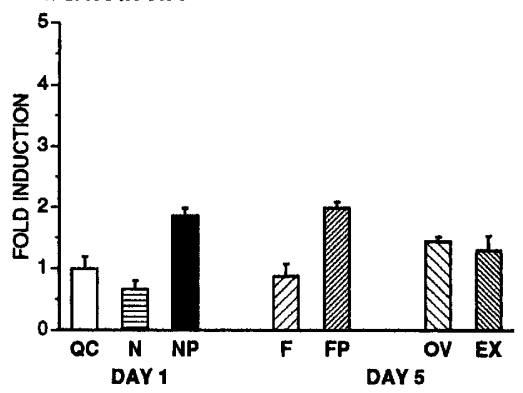

C HAT2 in NCM-HVCM

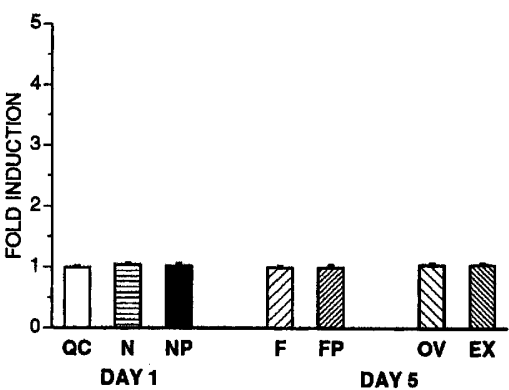

Figure 11: A comparison of ZENK and HAT2 expression in NCM-HVCM and HA regions of medial parasagittal brain sections (same level as in Fig. 8) of birds in the habituation, dishabituation, overtraining, and extinction groups and their controls from experiment 3 . For each region, all OD values were divided by the quiet control value to create a normalized ZENK fold-induction scale. Columns represent the mean normalized value for each group, and the error bars represent S.E.M. The groups shown for day 1 are (QC) quiet control; (N) novel song only; (NP) novel song paired with shock. Groups for day 5 are (F) familiar song (habituation); (FP) familiar song paired with shock (dishabituation); (OV) overtraining; and (EX) extinction. The QC, N, NP (day 1) and F and OV (day 5) are the same as in Fig. 10 and are included for purposes of comparison. For statistical analysis, see Results.

Brain areas other than NCM-HVCM may be involved in the processing of the stimuli used in this study, but NCM-HVCM was the only area analyzed where an interaction between the two stimuli was observed. The discussion will be centered on this region. Shock alone did not affect ZENK mRNA levels in NCM-HVCM, but its pairing with a song stimulus resulted in an enhancement of ZENK expression above that induced by song alone. The enhancement was not observed in control birds that received the same amounts of the two stimuli in an unpaired fashion and, in consequence, did not learn a conditioned association between song and shock. This suggests that the enhancement of ZENK expression in NCM-HVCM is related to the learning of an association between the two stimuli. Also compatible with this inter- pretation were two other observations related to ZENK levels in NCM-HVCM: (1) a first association of a familiar song and shock enhanced ZENK expression above song alone, and (2) ZENK levels decreased with repeated presentations of paired song and shock (overtraining groups). Both examples suggest that the novelty of an association enhances $Z E N K$ expression; as the novelty disappears there is less ZENK expression.

It is unlikely that the enhanced induction in the paired group was a result of either motor activity (number of jumps) or stress (number of shocks received) alone, as the unpaired and shock only groups controlled for these factors. Because no direct motor output from NCM-HVCM has been described and motor activity alone is insufficient to cause ZENK induction in NCM-HVCM, it

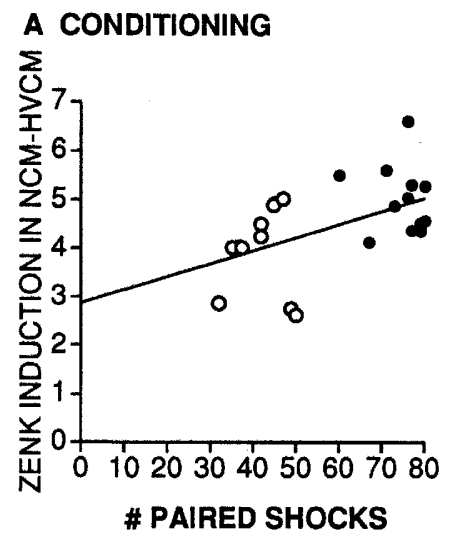

Figure 12: (A) Linear regression analysis correlating the level of ZENK induction in NCM-HVCM in the paired song and shock groups from experiments 1 (group 2) and 3 (group 3) with the total number of shocks paired with song that these birds received during their first and only training session $(n=22, \tau=0.304$, $P=0.048$ ). (O) Fast learners; (O) slow learners. $(B)$ Linear regression analysis of the relation between the level of ZENK induction in NCM-HVCM of the extinction group and the total number of avoidance responses the birds gave to song after shock was discontinued $(n=7$, $\tau=0.619, P=0.051$ ).

$$
\begin{array}{llllllllllllllll}
\hline & E & A & R & N & I & N & G & \begin{array}{l}
Q \\
75
\end{array} & M & E & M & O & R & Y
\end{array}
$$


also seems unlikely that the nature of the motor response that the birds gave was coded in this part of the brain. In contrast, the difference in $Z E N K$ levels in NCM-HVCM within the paired group (ZENK levels are higher in slow learners than in fast learners; see Figs. $9 \mathrm{~A}$ and 11A) suggests that fear-related stress does play a role but only when song is paired with shock. Both slow and fast learners promptly learned that song predicted shock; however, whereas slow learners were literally paralyzed by fear, fast learners learned quickly how to avoid the shock and presumably had less stress.

To our knowledge, this is the first time a difference in IEG induction has been seen between paired and "matched" yoked-unpaired controls. Our ability to detect this difference may have been related to the methodology employed. Many of the prior studies used Northern hybridization (Tischmeyer et al. 1990) of gross brain areas, whereas we used in situ hybridization and quantified $Z E N K$ levels in small and well-defined brain regions. Previous studies using in situ hybridization (Brennan et al 1992; Heurteaux et al. 1993) have also yielded well-defined differences of localized IEG regulation in the brain related to associative learning and have provided some good, yet less stringent controls.

The results from the overtraining and extinction groups in the present study raised some intriguing questions. For instance, although there was little improvement in shock avoidance after day 5, ZENK expression in the NCM of birds trained for 5 or 10 days remained higher than in birds receiving song only for the same period. In addition, within the extinction group, birds that extinguished their avoidance response more slowly had higher ZENK levels than birds that extinguished promptly. The following alternatives, which we cannot differentiate presently, may account for these effects:

1. Further Learning. Although during overtraining birds had learned the song/shock association well by the end of the fifth day of training, and their performance had reached an asymptote, further training resulted in temporal focusing of the response so that it was triggered by the third phrase of the song, which constitutes further learning. In addition, further training may have also resulted in a longer lasting memory. However, though there was new learning in the extinction group, expression was lowest in birds that extinguished the fastest, arguing in this case against an association between $Z E N K$ and further learning. Perhaps extinction is a special form of learning (LeDoux 1995).

2. Attention. Birds exposed to the same song "without shock" for several days may cease to attend to it; in contrast, birds in the overtraining group have to pay attention continuously to the song to avoid the shock, and this in itself may maintain higher levels of $Z E N K$ expression than in the song-habituated controls. However, if all of the induced expression in NCM-HVCM were related to attention, then expression on day 10 should be just as high as on days 1 and 5, which is not the case. Birds within the extinction group that extinguished more slowly, presumably continued to pay attention to the song stimulus longer than those that extinguished faster.

3. Stress. Fear related to the expectation of a shock was probably minimized in both the overtraining and extinction groups, as these birds had mastered the ability to avoid the shock. All the same, a remaining component of fear-related stress may have been induced during the few trials where birds in the overtraining group did not jump and got a shock. In the extinction group, birds that extinguished their responses more slowly-and that had the higher levels of ZENK expression-may have continued to dread the song stimulus longer than birds that showed prompt extinction of the avoidance response.

It is possible that any stimulus situation is accompanied by learning, and that some learning occurred in all of our control groups, for example, in the unpaired group (Rescorla and Wagner 1972). However, it is difficult to directly assess what and how much was learned in these control groups. In this regard, a useful measure is that of the novelty of the stimulus situation, which can be quantified more readily. Table 1 lists the 12 groups used for this study in increasing order of $Z E N K$ expression in NCM-HVCM. To each group was assigned a score that ranked the relative novelty of the song stimulus and a score that ranked the relative novelty of the pairing between song and shock. A "sum" score was calculated that reflected the overall novelty of the stimulus situation. There was a fairly good correspondence between the sum score and the extent of $Z E N K$ expression. The correspondence was not as close between $Z E N K$ expression and either of the other two scores by

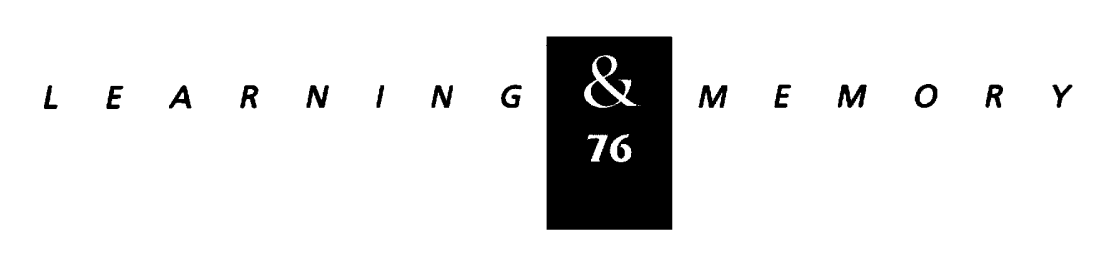


Table 1: Relation between ZENK expression in NCM-HVCM and song-associated novelty

\begin{tabular}{llccc}
\hline & & \multicolumn{3}{c}{ New information } \\
\cline { 3 - 5 } Group & ZENK in NCM & song & pairing & sum \\
\hline 1. Quiet Control & 1 & 0 & 0 & 0 \\
2. Shock Only & 1.5 & 0 & 0 & 0 \\
3. Familiar Song, day 10 & 1.5 & 1 & 0 & 1 \\
4. Overtraining, day 10 & 2.0 & 1 & 1 & 2 \\
5. Familiar Song, day 5 & 2.3 & 2 & 0 & 2 \\
6. Extinction, day 5 & 3.1 & 2 & 0 & 2 \\
7. Novel Song & 3.1 & 3 & 0 & 3 \\
8. Unpaired Novel Song and Shock & 3.3 & 3 & 0 & 3 \\
9. Overtraining, day 5 & 3.3 & 2 & 2 & 4 \\
10. Paired Familiar Song and Shock & 3.5 & 2 & 3 & 5 \\
11. Paired Novel Song and Shock, fast & 3.8 & 3 & 3 & 6 \\
12. Paired Novel Song and Shock, slow & 5.0 & 3 & 3 & 6 \\
\hline
\end{tabular}

The 12 groups from experiments 1, 3, and 4 are listed in order of increasing ZENK expression in NCM-HVCM (column 1). Each group was assigned two scores. The first (column 2) ranks the relative novelty of the song stimulus: 0 (no song), 1 (tenth session with song), 2 (fifth session with song), and 3 (first session with song). The second (column 3 ) ranks the relative novelty of the pairing between song and shock: 0 (no pairing), 1 (pairing, tenth session), 2 (pairing, fifth session), 3 (pairing, first session). A sum score (column 4) reflects the overall song-related novel information.

themselves. This finding is compatible with a role of $Z E N K$ in learning and confirms the results of a recent study in which the novelty of the song stimulus was shown to be an important determinant of ZENK induction levels in NCM (Mello et al. 1995).

In other regions of the forebrain, LPO, HA, and more rostral parts of $\mathrm{HV}$, shock alone induced $Z E N K$ expression. Some of these regions have also been found to have increased IEG expression after passive avoidance learning (Anohkin and Rose 1991 ) or visual imprinting (McCabe and Horn 1994) in chicks. Of relevant interest, during imprinting more c-fos expression in HA was found in poor learners than in good learners, which is similar to our results of ZENK in NCM-HVCM; however, just the opposite result was found in that study in intermediate medial hyperstriatum ventrale (IMHV) and hippocampus; more expression was seen in good learners. Thus, learning-related changes during imprinting in chicks were found in some of the same brain regions where shock induced changes in canaries. HA is a visual projection area (Hunt and Webster 1972; Karten et al. 1973; Miceli et al. 1975), and perhaps expression in this brain region is involved in visual associations of the context in which a stimulus (shock or imprinting) occurs. Because shock induced expression in our experiments in HA in all groups where shock occurred, it does not appear to be related to the association between song and shock.
In summary, song-induced $Z E N K$ expression in NCM-HVCM increased under conditions of associative learning and stimulus novelty. Recent studies (Mello et al. 1992, 1995; Mello and Clayton 1994; Chew et al. 1995) have suggested that NCM-HVCM plays a role in the formation of song auditory memories. The present report suggests, in addition, that NCM-HVCM plays a role in the formation of perceptual memories involving associations of song with other relevant stimuli in the birds' environment. A possible mechanism for the effects observed is that the novelty of the song stimulus or of its pairing with shock engages a general alertness/attention system (e.g., ascending catecholaminergic pathways) that then modulates the activation of the $Z E N K$ gene in an auditory area by song. Catecholaminergic immunoreactivity has been found in the songbird forebrain (Burd et al. 1986; Bottjer 1993), but the NCM-HVCM region has not been closely examined.

Our experimental paradigm may have a natural counterpart. Dominant canary males sing loudly, and subordinate males that try to sing are chased around and pecked (F. Nottebohm, unpubl.). Confrontations between songbirds often start by each bird countersinging when the other one starts. If this does not lead to spacing, and if one of the birds is an interloper in an established territory, then the territory owner will switch from singing to actual chase and physical attack.

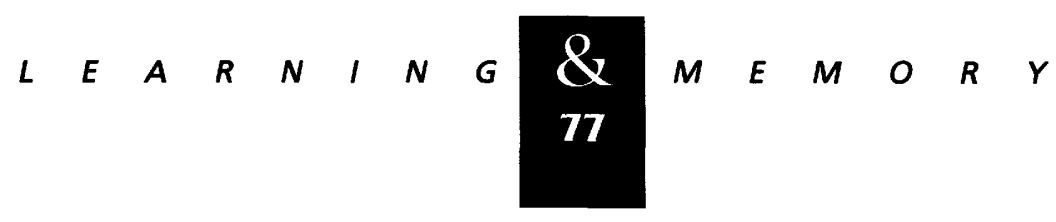


We see this happen often in canary colonies. Because of the natural association between song and aggression, the pairing of song and shock may have exploited this natural situation.

Conclusive evidence for the role of ZENK expression in NCM-HVCM in the formation of song perceptual memories can only be provided by experiments that selectively interfere with the expression of this gene in this brain region. In other systems, a step in this direction has been taken by studies that used antisense to block gene expression and prevent (Castro-Alamanacos and TorresAleman 1994) or impair (Tischmeyer et al. 1994) learning and to prevent long-term facilitation (Alberini et al. 1994). This approach can now be used to determine how ZENK affects the genomic expression, physiology, anatomy, circuitry, and behavioral relevance of cells in NCM-HVCM.

\section{Acknowledgments}

We thank David Clayton for stimulating discussions during the early stages of this project and for kindly providing us with the HAT2 canary gene. We thank Miriam Rivas and Julie Miwa for assisting with in situ hybridizations and Miriam Rivas and Bruce McEwen for critical reading of the manuscript. We thank Jeff Cynx and David Vicario for advice on statistical analysis. This research was supported by National Institute of General Medical Sciences Minority Access to Research Careers (MARC) predoctoral fellowship grant GM 12562 and by National Institute of Mental Health grant RO1 18343.

\section{References}

Anokhin, K.V. and S.P.R. Rose. 1991. Learning-induced increase of immediate early gene messenger RNA in the chick forebrain. Eur. J. Neurosci. 3: 162-167.

Alberini, C.M., M. Ghirardi, R. Metz, and E.R. Kandel. 1994. C/EBP is an immediate-early gene required for the long-term facilitation in aplysia. Cell 79: 1099-1114.

Anokhin, K.V., R. Mileusnic, I.Y. Shamakina, and S.P.R. Rose. 1991. Effects of early experience on c-fos gene expression in the chick forebrain. Brain Res. 544: 101-107.

Baily, M., E. Nikolaev, J. Beck, and L. Kaczmarek. 1992. Delayed c-fos expression in sensory cortex following sexual learning in male rats. Mol. Brain Res. 544: 101-107.

Bottjer, S.W. 1993. The distribution of tyrosine hydroxylase immunoreactivity in the brains of male and female zebra finches. /. Neurobiol. 24: 51-69.

Bouton, M.E. and D. Swartzentruber. 1991. Sources of relapse after extinction in Pavlovian and instrumental learning. Clin. Psychol. Rev. 11: 123-140.

Brennan, P.A., D. Hancock, and E.B. Keverne. 1992. The expression of the immediate-early genes c-fos, egr-1, and c-jun in the accessory olfactory bulb during the formation of an olfactory memory in mice. Neuroscience 49(2): 277-284.

Burd, G.D., J.A. Paton, H. Hemmings, J. Heintz, and F. Nottebohm. 1986. Dopamine innervation of newly-generated neurons in the forebrain of adult canaries. J. Histochem. Cytochem. 34: 109.

Campeau, S., M.D. Hayward, B.T. Hope, J.B. Rosen, E.J. Nestler, and M. Davis. 1991. Induction of the c-fos proto-oncogene in rat amygdala during unconditioned and conditioned fear. Brain Res. 565: 349-352.

Castro-Alamanacos, M.A. and I. Torres-Aleman. 1994. Learning of the conditioned eye-blink response is impaired by an antisense insuline-like growth factor I oligonucleotide. Proc. Natl. Acad. Sci. 91: 10203-10207.

Chew, S.J., C. Mello, F. Nottebohm, E. Jarvis, and D. Vicario. 1995. Decrements in auditory responses to a repeated conspecific song are long-lasting and require two periods of protein synthesis in the songbird forebrain. Proc. Natl. Acad. Sci. 92: 3406-3410.

Christy, B. and D. Nathans. 1989. DNA binding site of the growth factor-inducible protein Zif268. Proc. Natl. Acad. Sci. 86: 8737-8741.

Christy, B.A., L.F. Lau, and D. Nathans. 1988. A gene activated in mouse $3 \mathrm{~T} 3$ cells by serum growth factors encodes a protein with "zinc finger" sequences. Proc. Natl. Acad. Sci. 85: 7857-7861.

Edmunds, M. 1974. Defence in animals: A survey of anti-predator defences. Longman, Essex, UK.

Fordyce, D.E., R.V. Bhat, J.M. Baraban, and J.M. Wehner. 1994. Genetic and activity-dependent regulation of zif268 expression: Association with spatial learning. Hippocampus 4(5): 559-568.

George, J. and D.F. Clayton. 1992. Differential regulation in the avian song control circuit of an mRNA predicting a highly conserved protein related to protein kinase $C$ and the bcr oncogene. Mol. Brain Res. 12: 323-329.

Goelet, P., V. Castelucci, S. Schacher, and E. Kandel. 1986 The long and the short of long-term memory-A molecular framework. Nature 332: 419-422.

Gupta, M.P., M. Gupta, R. Zak, and V.P. Sukhatme. 1991. Egr-1, a serum-inducible zinc finger protein, regulates transcription of the rate cardiac-myosin heavy chain gene. $J$. Biol. Chem. 266: 12813-12816.

Heurteaux, C., C. Messier, C. Destrade, and M. Lazdunski. 1993. Memory processing and apamin induce immediate

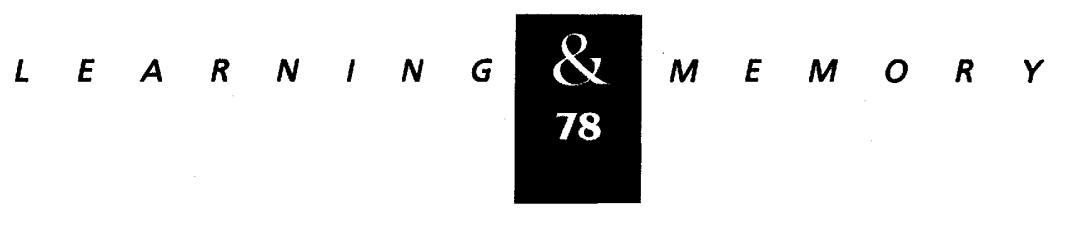


early gene expression in mouse brain. Mol. Brain Res. 3: 17-22.

Hunt, S.P. and K.E. Webster. 1972. Thalamo-hyperstriate interrelations in the pigeon. Brain Res. 44: 647-651.

Kaczmarek, L. 1993. Molecular biology of vertebrate learning: Is c-fos a new beginning. I. Neurosci. Res. 34: 377-381.

Kamin, L.J. 1956 Effects of termination of the CS and avoidance of the US on avoidance learning. I. Comp. Physiol. Psychol. 49: 420-424.

Karten, H.J., W. Hodos, W.J.H. Nauta, and A.M. Revzin. 1973. Neural connections of the "Visual Wulst" of the avian telencephalon. Experimental studies in the pigeon (Columba livia) and owl (Speotyto cunicularia). J. Comp. Neurol. 150: $253-278$

Lamph, W., P. Wamsley, P. Sassone-Corsi, and I. Verma. 1988. Induction of proto-oncogene JUM/AP1 by serum and TPA. Nature 334: 629-631.

LeDoux, J.E. 1995. Emotion: Clues from the brain. Annu. Rev. Psychol. 46: 209-235.

Lemaire, P., O. Relvelant, R. Bravo, and P. Charnay. 1988. Two mouse genes encoding potential transcription factors with identical DNA-binding domains are activated by growth factors in cultured cells. Proc. Natl. Acad. Sci. 85: 4691-4695.

Lim, R.W., B.C. Varnum, and H.R. Hersham. 1987. Cloning of tetradecanoyl phorbol ester-induced "primary response" sequences and their expression in density-arrested Swiss 3T3 cells and a TPA non-proliferative variant. Oncogene 1: $263-270$.

Maleeva, N.E., K.V. Ivolgina, K.V. Anokhin, and S.A. Limborskaja. 1989. Analysis of the expression of the c-fos protooncogene in the rat cerebral cortex during learning. Genetica 25: 1119-1121.

Marks, I.M. 1987. Fear behaviors: The four strategies. In Fears, phobias, and rituals: panic, anxiety, and their disorders, pp. 53-81. Oxford University Press, New York.

McCabe, B.J. and G. Horn. 1994. Learning-related changes in Fos-like immunoreactivity in the chick forebrain after imprinting. Proc. Natl. Acad. Sci. 91(24): 11417-11421.

Mello, C.V. and D.F. Clayton. 1994. Song-induced ZENK gene expression in auditory pathways of songbird brain and its relation to the song control system. I. Neurosci.

14(11): 6652-6666.

1995. Differential induction of the ZENK gene within the avian forebrain and song control circuit after metrazole-induced depolarization. J. Neurobiol. 26(1): 145-161.

Mello, C.V., D.S. Vicario, and D.F. Clayton. 1992. Song presentation induces gene expression in the songbird forebrain. Proc. Natl. Acad. Sci. 89: 6818-6822.

Mello, C.V., F. Nottebohm, and D. Clayton. 1995. Repeated exposure to one song leads to a rapid and persistent decline in an immediate early gene's response to that song in zebra finch telencephalon. I. Neurosci. (in press).

Miceli, D., J. Perichoux, and J. Reperant. 1975. The retino-thalamo-hyperstriatal pathway in the pigeon (Columba livia). Brain. Res. 100: 125-131.

Millbrandt, J. 1987. A nerve growth factor encodes a possible transcriptional regulatory factor. Science 238: 797-799.

Morgan, J.I. and Curran. 1989. Stimulus-transcription coupling in neurons: Role of cellular immediate early genes. Trends Neurosci. 12: 423-433.

Nastiuk, K.L., C.V. Mello, J.M. George, and D.F. Clayton. 1994. Immediate-early gene responses in the avian song control system: Cloning and expression analysis of the canary c-jun cDNA. Mol. Brain Res. 27: 299-309.

Nikolaev, E., B. Kaminska, W. Tischmeyer, H. Matthies, and L. Kaczmarek. 1992a. Induction of expression of genes encoding transcription factors in the rat brain elicited by behavioral training. Brain Res. Bull. 28(3): 479-484.

Nikolaev, E., T. Werka, and L. Kaczmarek. 1992b. C-fos protooncogene expression in rat brain after long-term training of two-way active avoidance reaction. Behav. Brain Res. 48: 91-94.

Nishimura, T and P. Vogt. 1988. The avian homolog of the oncogene jun. Oncogene 3: 659-663.

Nottebohm, F., T.M. Stokes, and C.M. Leonard. 1976. Central control of song in the canary, Serinus canarius. /. Comp. Neurol. 165: 445-471.

Nottebohm, F., D.B. Kelly, and J.A. Paton. 1982. Connections of vocal control nuclei in the canary telencephalon. J. Comp. Neurol. 207: 344-357.

Pavlov, I. 1927. Conditioned reflexes. Oxford University Press, UK.

Paylor, R., R.S. Johnson, V. Papaioannou, B.M. Spiegelman, and J.M. Wehner. 1994. Behavioral assessment of $\mathrm{c}$-fos mutant mice. Brain Res. 651: 275-282.

Rescorla, R.A. 1969. Conditioned inhibition of fear. In Fundamental issues in associative learning (ed. W.K. Honig and N.J. Mackintosh), pp. 65-89. Dalhousie University Press, Halifax, Nova Scotia, Canada.

Rescorla, R.A. and A.R. Wagner. 1972. A theory of Pavlovian conditioning: Variations in the effectiveness of reinforcement and nonreinforcement. In Classical conditioning II: Current research and theory (ed. A.H. Black

$$
\begin{array}{llllllllllllllll}
\hline & E & A & R & N & I & N & G & \begin{array}{l}
\text { X } \\
79
\end{array} & M & E & M & O & R & Y
\end{array}
$$




\section{Jarvis et al.}

and W.F. Prokasy), pp. 64-99. Appleton-Century-Crofts, New York.

Rose, S.P.R. 1991. How chicks make memories: The cellular cascade from c-fos to dendritic remodeling. Trends Neurosci. 14: 390-397.

Schwartz, B, 1984. Aversive control of behavior: Punishment and avoidance. In Psychology of learning and behavior, pp. 192-233. Norton and Company, New York.

Siegel, S. 1956. The case of two related samples; The case of two independent samples. In Nonparametric statistics for the behavioral sciences, pp. 75-83 and 116-127. McGraw-Hill, New York.

Smith, M.A., S. Banerjee, P.W. Gold, and J. Glowa. 1992. Induction of $c$-fos mRNA in rat brain by conditioned and unconditioned stressors. Brain Res. 578: 135-141.

Sokal, R.R. and F.J. Rohlf. 1969. Assumptions of analysis of variance. In Biometry: The principles and practice of statistics in biological research, p. 401. W.H. Freeman and Company, San Francisco, CA.

Sukhatme, V.P., X. Cao, L.C. Chang, C.H. Tsai-Morris, D. Stamenkovitch, P.C.P. Ferreira, D.R. Cohen, S.A. Edwards, T.B. Shows, T. Curran, M.M. LeBeau, and E.D. Adamson. 1988. A zinc finger gene coregulated with c-fos during growth and differentiation, and after cellular depolarization. Cell 53: $37-43$.

Tischmeyer, W., L. Kaczmarek, M. Strauss, R. Jork, and H. Matthies. 1990. Accumulation of $c$-fos mRNA in rat hippocampus during acquisition of a brightness discrimination. Behav. Neural. Biol. 54: 165-171.

Tischmeyer, W., R. Grimm, H. Schicknick, W. Brysch, and K. Schlingensiepen. 1994. Sequence-specific impairment of learning by c-jun antisense oligonucleotides. NeuroReport 5: 1501-1504.

Weiss, J.M. 1970. Somatic effects of predictable and unpredictable shock. Psychosomat. Med. 32: 397-408.

Weiss, J.M. 1977. Ulcers. In Psychopathology: Experimental models (ed. D. Maser and M.E.P Seligman), pp. 232-269. W.H. Freeman, San Francisco, CA.

Wisden, W., M.L. Errington, S. Williams., S.B. Dunnet, C. Waters, D. Hitchcock, G. Evan, T.V.P. Bliss, and S.P. Hunt. 1988. Differential expression of immediate early genes in the hippocampus and spinal cord. Neuron 4: 603-614. 


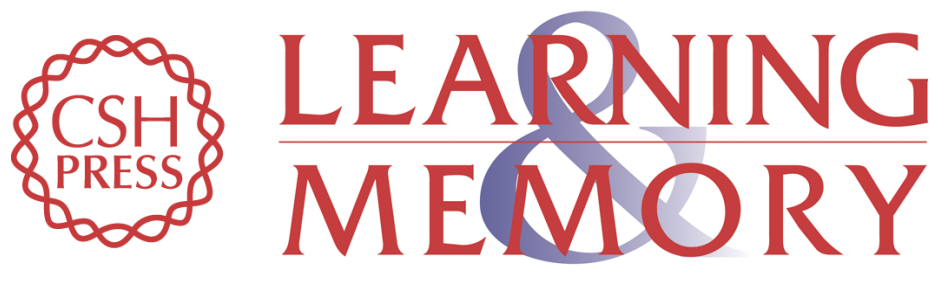

\section{Associative learning and stimulus novelty influence the song-induced expression of an immediate early gene in the canary forebrain.}

E D Jarvis, C V Mello and F Nottebohm

Learn. Mem. 1995, 2:

Access the most recent version at doi:10.1101//m.2.2.62

References This article cites 48 articles, 11 of which can be accessed free at: http://learnmem.cshlp.org/content/2/2/62.full.html\#ref-list-1

License

Email Alerting

Receive free email alerts when new articles cite this article - sign up in the box at the Service top right corner of the article or click here. 